\title{
The value components of contract farming in contemporary capitalism
}

\author{
Alex Dubb
}

\begin{abstract}
Contract farming (CF) has generally been understood as, essentially, a market institution-by both (approving) "mainstream" and (critical) "radical" perspectives. Analyses of relations of production have, meanwhile, tended towards a problematic "peasantist" frame, where contracts undermine farmer "autonomy" in processes of "flexible" corporate agro-industrial restructuring. This paper argues that a materialist analysis of $\mathrm{CF}$ from within capital-labour relations offers a stronger conceptual foundation for re-synthesizing questions of market-power. It first argues that radical notions of "peasant subsumation" conceptually mirror Marx's "formal subsumption of capital" but underplay dynamics of "real subsumption" accompanying capitalism's wider development. Drawing on the "petty commodity production" concept, it then argues that CF's "flexibility" rests in its differential content. CF's fungibility to contradictory movements of "integration" and "dispersion" enables it to emphasize different methods of surplus appropriation under shifting conditions; each corresponding to a different dominant social tendency. On the one hand, conditions of market expansion inspire integration for relative surplus appropriation through raised productivity, and CF tends to act as a "tool of proletarianization" in the wider centralization of capital. On the other, conditions of contraction motivate the dispersal of unvalorized capital, prompting efforts to raise absolute surplus appropriation, and CF tends to act as a "tool of differentiation" to concentrate agricultural capital.
\end{abstract}

\section{1 | Introduction}

As a legal form with appearance of neutrality and universality, the contract between farmer and processor is much like the wage contract between "free" labourer and employer described and analyzed by Marx: the legal form conceals (and yet, on analysis, reveals) the system of social relations beneath it, its very abstractness providing a powerful strategy for capital accumulation and exploitation. (Wilson, 1986, p. 47)

Contract farming (CF) has enjoyed a renascence in academic and developmental literatures, partly by its renewed promotion as a "socially inclusive business model" in controversial "large-scale land investments". For critics, however, CF represents an insidious vehicle of "commercialization", often attending "land grabs" and portending reduced food production, consumption, and nutrition. Reviews of CF literature and comparison with other productive forms have elucidated the polarization of debate, but emphasize (above all) the 
diversity of $\mathrm{CF}$ schemes and their outcomes-and remain cautious about generalization amidst severe methodological insufficiencies; in particular, a dearth of sufficiently broad, disaggregated, and longitudinal data (Oya, 2012; Smalley, Sulle, \& Malale, 2014). ${ }^{1}$

CF's sheer diversity and paucity of data are significant observations, but-rather than seek generalizable empirical claims about CF's outcomes or taxonomic features-this paper pursues a more abstract analytical frame from materialist political economy, in order to interrogate how "real processes [are] giving rise to a variety of contradictions" (Gibbon \& Neocosmos, 1985).

The paper proceeds in two main sections. The first critically reframes approaches to CF, distinguishing those locating its central mechanisms in exchange and circulation from those centred on relations of production. In the former case, I argue that critiques of $\mathrm{CF}$ as a lever of "market-power" appropriately observe its part in (or reliance on) diminishing markets, but inadvertently rehearse a Liberal analytic by relying on monopsony relations. However, critiques focused on relations of production (most seminally by Little \& Watts, 1994) have advanced ambiguous/ underdeveloped conceptualizations of CF's mechanisms, variously construed as a "flexible", "post-Fordist" form of "corporate" dispersal, agro-restructuring, and labour-market fragmentation, as well as an instrument of integration-most problematically, as the sole vehicle of capitalist relations and the "subsumation" of erstwhile "autonomous" peasantries.

The second section argues that a materialist understanding of capitalist production offers a more coherent conceptual foundation for CF's contradictory forms and social tendencies. In particular, CF's true flexibility-rather than simply reflecting multifarious terms across diverse social formations-resides in its dynamic engagement with producers as both capital and labour under shifting conditions, each corresponding to a contradictory change in industrial organization and underlying social tendency. To advance this argument, I illustrate the parameters of CF's mechanisms within the confines of value relations, and introduce various assumptions to conceptually control for different dynamics. It should be emphasized outright that these assumptions do not represent "ideal types" (Sayer, 1992) to be "matched" with any given enterprise's formal characteristics.

The argument proceeds in five parts, and it is useful to review its core features. Although this pre-empts the paper's analytical points, the argument's abstract nature-and schematic models employed to demonstrate it-can be burdensome to the reader if the full, rather complicated, architecture of argument is lost, or indistinct from points of digression and detail.

I first seek to distinguish general processes and compulsions of capitalist commodity production from CF's particular mechanisms. As a point of departure, I show that dynamics

\footnotetext{
1 This has not prevented ongoing (largely policy orientated) attempts to glean generalizable "lessons" from systematic reviews of empirical case study material, with a particular focus on CF's "effects" and their association with various enabling conditions (see, e.g., Minot, 2011; Ton et al., 2015).
} 
attributed to CF by Watts' (2010) notion of "peasant subsumation" are starkly mirrored (albeit stripped of their materialist content) in Marx's "formal subsumption of capital", pertaining to wider processes of commodification in transition to capitalism. More problematic is the omission of Marx's paired concept, the "real subsumption of capital"; wherein general and anonymous rises in the social productivity of labour "suppress" "independent" production-irrespective of the form of the contract.

Having jettisoned rarefied notions of "peasantness", I restate the petty commodity production (PCP) concept as a more robust analytic of small-scale production. Before turning to CF in particular, the section first shows how, under static technological conditions, PCPs' internalization of the capital-labour relation and propensity for "self-exploitation" competitively compels the "release" of surplus, and discourages accumulation in agriculture (i.e. independent of contractual "squeezing”).

The final three parts elaborate the particular relevance of the contract form. First, wherein contractors engage farmers as labour, $\mathrm{CF}$ serves as a mechanism of vertical integration in the broader centralization of capital. ${ }^{2}$ Here, contracts "capture" PCPs' released surplus, and competitively disabuse capitalist farmers of theirs to lower the contracting enterprise's value composition. As agricultural labour does not valorize agricultural "capital", the latter increasingly stands as a mere "branch" of downstream production. By alienating producers from their product, the contract is hardly distinguishable from a wage, and CF "proletarianizes without dispossessing" (Watts, 1994, p. 81) farmers. Although this model presumes that monopsony contractors wield market-power, it is demonstrated how this leverage can be competitively compelled rather than arbitrarily exercised under static technological conditions.

The next part elaborates the role of technical change within and without the contract's boundaries. As conceptually introduced by Marx's "real subsumption of capital", a rising social productivity of labour accompanying technical change "suppresses" PCPs utilizing "old" methods of production. The commodity's devaluation eliminates surplus erstwhile "released" by petty producers, requiring intensified self-exploitation as a matter of competitive survival. Within $\mathrm{CF}$, tendencies to integration remain, but PCPs are no longer at the competitive vanguard, and their poverty does not see extra surplus "captured" by the processor. Hence, technologies disbursed under CF may appear to "control" or "suppress" small producers simply unable to meet socially average levels of productivity. Their dejection, rather than originating in the contract, emanates from general processes of social differentiation accompanying the concentration of agricultural capital. Indeed, technologies disbursed under contract may be necessary to meet these pressures.

\footnotetext{
${ }^{2}$ Marx (1976, pp. 775-780) distinguishes the "centralization" and "concentration" of capital as closely related but distinct processes of accumulation. Fine and Saad-Filho (2004, p. 86) summarize the basic distinction. Concentration concerns the process whereby "profits may be re-invested, amassing capital over time". As a corollary, more capital is required to enter production, gradually resulting in fewer highly capitalized producers. Centralization, by contrast, occurs when capitalists "borrow and merge, gathering the existing resources of capitalist production", without necessitating an increase in social wealth or productivity as such. Neither directly necessitates vertical integration, although both in principle can underlie it. Here, "centralization" is emphasized to interrogate CF's role in mediating a "change in the distribution of already existing capitals" (Marx, 1976, p. 779).
} 
The final part considers CF's polar and contradictory possibility, whereby contracts serve as mechanisms of dispersion, and engage producers as a distinct circuit of capital. Here, contracts shift unvalorized capital costs on to agricultural producers, and appear distinctively (but not exclusively) as "tools of differentiation" (Wilson, 1986). The contractee-whether capitalist farmer or PCP-directly appropriates surplus labour, but accentuating pressures of sunk capital costs catalyse agricultural capital's differentiation and concentration. Importantly, the processor's valorization is not enhanced by extorting "extra" surplus, but evading sunk capital costs, and, potentially, reduced raw material prices following the uptake of new technologies. Prompted by Wallerstein and Hopkins (1994), I suggest that forms of CF will tend in this alternative direction under conditions of economic contraction. As small farmers can be "suppressed" both as a result of contractual "squeezing" and owing to their under-capitalization, their poverty/poor working conditions and tendency to proletarianization are not sufficient evidence of CF's content, being consistent with both "poles".

\section{The problem with contract farming}

The plurality of perspectives on CF is nothing new. Over 20 years ago, Glover and Kusterer (1990, pp. 12-13) discerned three key literatures: (a) evaluation studies; (b) a constellation of "pro-peasant" academics and activists critical of agribusiness; and (c) a "business school", focused on corporate behaviour and management. These were subsequently followed by approaches from (d) "economic sociology" and/or "political economy" and (e) New Institutional Economics.

In his review of CF literatures, Oya (2012, p. 5) acutely observes that these categories mix "methodological and ideological criteria"-but the latter generally steer the course of debate, as ideologically opposed authors caricature one another's interpretations. Such dissent is paired with an inadequate methodological tendency to glean stylized outcomes from case studies-all in a general context of insufficient disaggregated longitudinal data (Oya, 2012).

Yet, while certainly posing difficulties for assessing CF's general impact, it is not clear that this empirical barrier impedes an analysis of CF's mechanisms. This is necessary to interrogate the parameters of CF's "potentialities" (Sayer, 2000, p. 97), and hence critically probe its influence over broader and complex social processes in diverse social formations. Divisions over CF do not arise, simply, from lack of evidence: they are buttressed by theoretical ambiguity surrounding CF's mechanisms and relation to broader processes. Put differently, the issue is not just one of categorizing different approaches to $\mathrm{CF}$, but of disentangling their internal eccentricities and contradictions to garner deeper understanding.

To tease insights from a literature where ideology and methodology indeed mix, I compress the above categories into a broader distinction: between approaches to $\mathrm{CF}$ from standpoints of technicality in "mainstream" liberal developmentalism (hereafter referred to as "Liberal" standpoints); and from critique in Radical Political Economy (RPE). This is not intended to replace (or update) Glover and Kusterer's (1990) taxonomy of perspectives; which express 
more concrete combinations of implicit methodological, theoretical, and political criteria. Instead, it is a device to distinguish conceptualizations of CF's mechanisms, on the one hand, as market-institutional (whether critically or approvingly) and, on the other, from within relations of production. As such, it does not seek to pigeonhole authors, or construct mutually exclusive "camps", but to probe the conceptual robustness and limits of different mechanisms and processes underlying a plurality of perspectives.

\section{1 | What is contract farming?}

A foundational difficulty in theorizing $\mathrm{CF}$ is its chimeric character. Its array of forms induces almost all approaches to emphasize its diversity. Hence, setting CF's conceptual parameters is important, and usually underpins further semi-empirical typologies. I use the definition provided by Little and Watts (1994, p. 9) because of its wide ambit, where CF is understood to encompass:

[1] forms of vertical coordination between growers and buyers-processors [2] that directly shape production decisions through [3] contractually specifying market obligations (by volume, value, quantity, and, at times, advanced price determination); [4] provide specific inputs; and [5] exercise some control at the point of production (i.e., a division of management functions between contractor and contractee). (square brackets added)

At the outset, $\mathrm{CF}$ is explicitly framed as a vertical interface between buyer-processors and growers, as indicated by interval [1]. Consequently, relations and dynamics within the units of either grower or buyer-processor are not directly internalized into this definition; nor are "horizontal" relations (particularly competition) among actors in the same chain or in different sectors. While these may be (and usually are) flagged as important in concrete circumstances, they are not specified here as carrying explanatory capacity in understanding CF.

Intervals [3], [4], and [5] indicate different types of relationships that CF might entail. Little and Watts (1994, p. 73) note that this selection is premised on Mighell and Jones' (1963) distinction between, on the one hand, "production contracts"-where the "labour process is determined, controlled and supervised"-and, on the other, "market-specification contracts (future-purchase agreements)" and "resource contracts (growers are provided seed credit and technology)". In contrast to the rigid "vertical" specification of [1], these types are not mutually exclusive, and any combination of [3], [4], or [5] still qualifies as CF.

But despite the diversity that this flexibility implies, there is an implicit division between two axes. On one side, [3] and [4] clearly represent relationships of exchange and circulation (in specifying conditions for sale, input provision, and technical services); while on the other, [5] pertains to relations in production itself. Little and Watts (1994) clearly mean to intimate a relationship between each by way of [2], but without specifying its nature. This central ontological ambiguity is at the heart of the "problem" of understanding CF.3

\footnotetext{
${ }^{3}$ Little and Watts' (1994) definition of CF is accompanied by many others with their own idiosyncratic phrasing and emphasis on various details, but remains amongst the most complete and clear in its conceptual parameters, and directly includes questions of "control" over production; a key area of engagement in this paper. Another commonly utilized definition is provided by Prowse (2012,
} 


\subsection{The market is dead, long live the market!: Relations of exchange and "power" in contract farming}

One of CF's central ambiguities is its identity as a "market" institution. Within Liberal approaches, CF is conceived along a spectrum of institutional forms, ranging from spot markets to full vertical integration (Sartorius \& Kirsten, 2005), as a mechanism to establish markets erstwhile hindered by "distortions" or asymmetries. Differential technical requirements of a particular crop are one key set of determinants, such as perishability, maintenance-intensive gestation periods, and the presence of economies of scale (Binswanger \& Rosenzweig, 1986, p. 528).

In this regard, $\mathrm{CF}$ has a special relevance for New Institutional Economics (NIE), which explicitly understands all economic enterprises as bundles of contracts bounded by the costs and risks of transactions (Coase, 1937; Kirsten, Karaan, \& Dorward, 2009, p. 43). For NIE, $\mathrm{CF}$ is therefore a mechanism to mutually divide and manage risks between farmers and processors-configured by the level of uncertainty, frequency of transactions, and specificity of assets involved. NIE's methodology tends to be highly taxonomic, linking discrete contractual and market characteristics-and lending a technical character to exchange relations (Grosh, 1994; Sartorius \& Kirsten, 2005) (Table 1).

For some critics, however, the reverse is true: rather than encouraging market relations, $\mathrm{CF}$ inhibits them. Wilson (1986, p. 58) describes this essential logic, whereby contractual obligations "lock" producers into monopsony/monopoly relations in selling produce and/or procuring inputs and services-including credit. In addition to concentrating industrial, merchant, and interest-bearing capitals in contractual "packages", a vicious circle ensues, whereby contracting diminishes open markets and compels others to extend contracts to secure raw material. The contention that $\mathrm{CF}$ is a market-diminishing institution is strengthened by observations that "success" often hinges on precluding "cheating" by juridical mechanisms, or an absence of alternatives to company monopoly/monopsony (Glover \& Kusterer, 1990; Oya, 2012; Williams \& Karen, 1985). "This is striking", observes Oya (2012, pp. 8-9), "as it implies that CF schemes are sustainable with less or no market competition" (emphasis in original). Whether formally enforced (via contract) or informally, $\mathrm{CF}$ is hence a mechanism of direct extortion or "squeezing" (Bernstein, 1988, p. 265), in governance over pricing and supply access-including the manipulation of "standards". Rather than "sharing" risk, contracts might be utilized to shift risk.

p. 12) below, which is also based on Mighell and Jones (1963) but draws on Hamilton (2008) to add (the seemingly arbitrary and constraining) conditions of a fixed-term contract and "farmer" ownership/control over land. Notwithstanding a more legalistic language and omission (or disguise) of direct relations in production (and excluding "production contracts"?), Prowse's definition can be divided into the same intervals identified for Little and Watts (1994): "[1] a contractual arrangement for a fixed term between a farmer and a firm, agreed verbally or in writing before production begins, [4] which provides resources to the farmer and/or specifies one or more conditions of production [2], [3] in addition to one or more marketing conditions, for agricultural production on land owned or controlled by the farmer, which is non-transferable and gives the firm, not the farmer, exclusive rights and legal title to the crop". 
TABLE 1 An example of a NIE contract/vertical coordination continuum

\begin{tabular}{|c|c|c|c|c|c|}
\hline \multirow[t]{4}{*}{ Contract characteristics } & Grade 1 & Grade 2 & Grade 3 & Grade 4 & Grade 5 \\
\hline & \multicolumn{5}{|c|}{ Vertical coordination continuum } \\
\hline & $\begin{array}{l}\text { Classical } \\
\text { contracting }\end{array}$ & $\begin{array}{l}\text { Neoclassical } \\
\text { contracting }\end{array}$ & $\begin{array}{l}\text { Neoclassical } \\
\text { contracting }\end{array}$ & $\begin{array}{l}\text { Bilateral } \\
\text { relational }\end{array}$ & Unified relational \\
\hline & Spot market & $\begin{array}{l}\text { Specification } \\
\text { contracting }\end{array}$ & Strategic alliance & $\begin{array}{l}\text { Formal } \\
\text { cooperation }\end{array}$ & $\begin{array}{l}\text { Full vertical } \\
\text { integration }\end{array}$ \\
\hline 1. Frequency & Low & Low-medium & Medium & High & Very high \\
\hline 2. Asset-specificity & Low & Low-medium & Medium & High & Very high $X X^{a}$ \\
\hline \multicolumn{6}{|l|}{ 3. Uncertainty } \\
\hline Ability to walk away & Yes & Yes/lower & Less $X^{a}$ & Low & No \\
\hline Substitutes & Yes & Yes/less & Less & No & No $X X^{a}$ \\
\hline Duration & Short & Short/medium & Medium & Long & Very long $X X^{a}$ \\
\hline Ex-ante control & High & Lower & Low & No & No $X X^{a}$ \\
\hline Ex-post importance & Low & Low/medium & Medium & High & Very high $X X^{a}$ \\
\hline Information shared & Low & Low/medium & Medium & High & Extensive $X X^{a}$ \\
\hline Contract enforcement & Legal & Complex-legal & Complex $X X^{a}$ & Bilateral & Hierarchy \\
\hline Summary & & & 2 & 0 & 7 \\
\hline
\end{tabular}

Source: Reproduced from Sartorious and Kirsten (2005, p. 86).

'These indicate Sartorious and Kirsten's "subjective" assessment of a particular contract farming scheme in Swaziland.

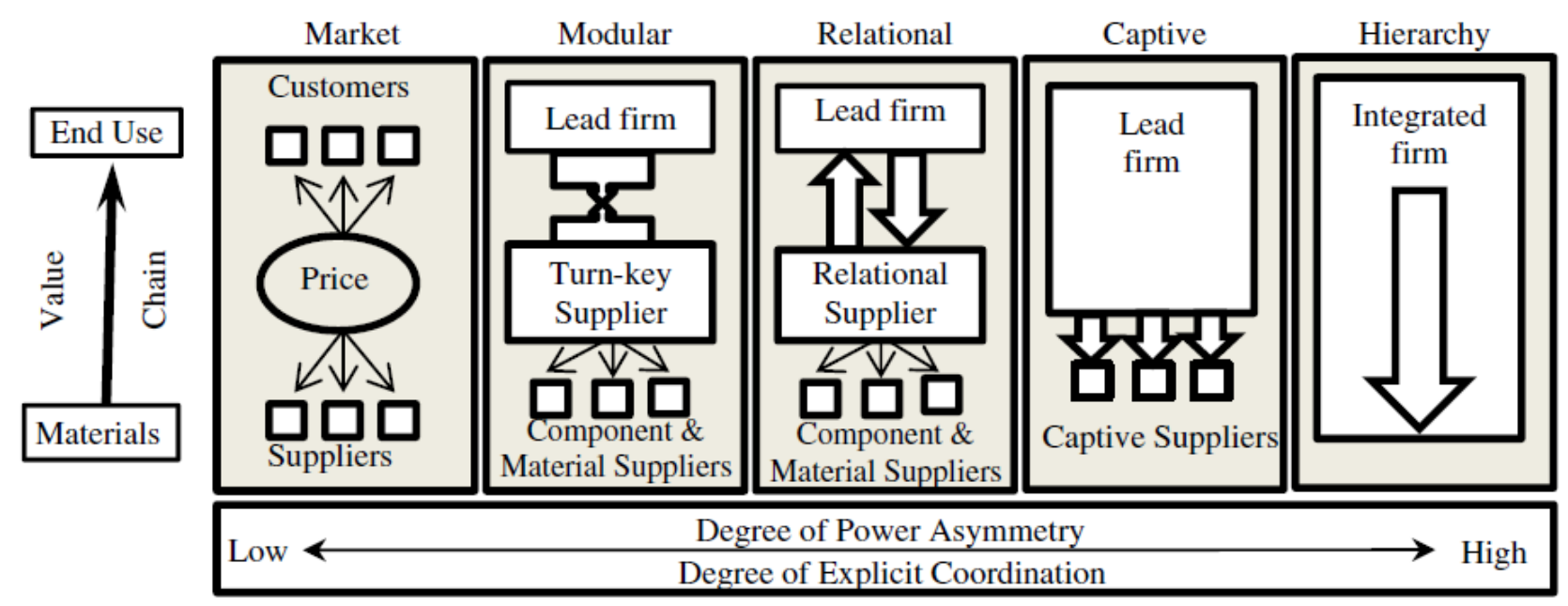

FIGURE 1 Global value chain governance types

Source: Reproduced from Gereffi et al. (2005). 
TABLE 2 Key determinants of global value chain governance

$\begin{array}{llllll}\text { Governance type } & \text { Market } & \text { Modular } & \text { Relational } & \text { Captive } & \text { Hierarchy } \\ \text { Complexity of transactions } & \text { Low } & \text { High } & \text { High } & \text { High } & \text { High } \\ \text { Ability to codify transactions } & \text { High } & \text { High } & \text { Low } & \text { High } & \text { Low } \\ \text { Capabilities in the supply-base } & \text { High } & \text { High } & \text { High } & \text { Low } & \text { Low } \\ \text { Degree of explicit coordination and power asymmetry } & \text { Low } & \leftarrow & - & \rightarrow & \text { High }\end{array}$

Source: Reproduced from Gereffi et al. (2005).

Yet a closer look at the argument's content instead of its politics (the method as opposed to the ideology, to invoke Oya's distinction) reveals a consonance between NIE and RPE. In both, "power" relations within CF concern market-power-in the guise of "bargaining power", determined by the institutional form governing exchange. This is remarkably close to the "chain" analyses that have emerged as a mainstay of political economy. In addition to a primarily vertical frame, both foreground contracts as mechanisms of "governance", "coordination", and "power", impacting distributions of cost and risk (Gereffi, Humphrey, \& Sturgeon, 2005; Gibbon, Bair, \& Ponte, 2008).4 As illustrated by Figure 1 and Table 2, the identity of "power" lacks any clear independence from "coordination" and "integration", and is notably similar to the NIE framework reproduced above in Table 1.

This leads RPE to a sort of circularity, where "power" precedes and is expressed through contracts, yet is also explained by them (Starosta, 2010). The irony of neoclassical and NIE theorists ultimately advocating against markets through $\mathrm{CF}$ is matched by the (implicit or explicit) foundation of RPE and GVC critiques of monopoly/monopsony violating Liberal competitive markets. If open-market relations are not advocated for, the suggestion seems to be that eliminating contracts as tools of "power" requires their replacement by better or more effectively enforced ones- the solution to the problem of contracts is better contracts! Otherwise, if only CF's "market-distorting" character is emphasized, the radical critique "there are no perfect markets" is transformed from insight to lament: "The market is dead, long live the market!"

\section{3 | Contract farming, "peasants", and "control" over production}

The gravamen thus far is that understanding $\mathrm{CF}$ as a mechanism of market-power alone does not mark a fundamental break from Liberal theorizations.

However, where RPE offers potentially penetrating insight into $\mathrm{CF}$ is in relations in production. As intervals [2] and [5] in the extract from Little and Watts (1994-quoted above) indicate, questions of how CF "shapes" or "controls" production are key. But here, too, lie conceptual pitfalls and lacunae, though of a more subtle nature.

\footnotetext{
${ }^{4}$ This summary certainly does injustice to diversity within and nuances between the global commodity chain (GCC), the global value chain (GVC), and the more recent global production network (GPN) literatures. Gibbon et al. (2008) provide a good overview of the salient debates and methodological hurdles.
} 
Most ambiguous is what constitutes "control". As highlighted by Oya (2012), in their original definition Little and Watts (1994, p. 9) carefully exclude "contractual marketing arrangements that presupposed no intervention in production". However, this initial rigidity is abandoned in many of the case studies analysed, where contracts may/may not be formally constituted-or, if so, are done via some combination of "market-specification" and "resource" contracts. To evade contradiction, Watts (1994, p. 28) maintains that control is effected by a "systemic link" between "product and factor markets", and, following Braverman (1974), posits that this cleaves a "separation between the execution and conception" of production. Little and Watts (1994) consequently define themselves into a corner: either they stick to cases where contracts control labour directly-and consequently exclude many schemes from consideration-or they must demonstrate how this "systemic link" is particular to CF and not to other forms of farming.

For Watts (2010), this is mainly resolved by conceiving contemporary CF, first, as a vehicle for capitalism to "penetrate" erstwhile "autonomous", "peasant" labour processes tout court and, second, as a form of "flexible accumulation" particular to a "post-Fordist" (Goodman \& Watts, 1994, p. 34) phase of globalizing capitalism. Put directly by Watts (2010, p. 277):

The rise of contracted high-value food through agribusiness has had the effect of integrating peasants juridicially as much as economically into the both the global market and the transnational firm. It is rarely the poorest of the peasants but Lenin's [sic] middle and rich peasants, who became part of increasingly mechanized and highly regimented work regimes ... [where] the household economy resembles a piecework system in which one of the tenants of "peasantness"-the autonomy of the labour process-is radically compromised by the demands of the contract ... At the very least, the subsumation of peasants directly into the firm as growers represents a distinctive, if not totally original, way in which peasants may persist, producing low-cost commodities in the midst of advanced global capitalism.

The first proposal, that CF undermines "autonomous" labour processes, relates to debates about whether distinct "peasant" logics exist astride capitalist relations (Bernstein, 2009; Chayanov, 1966; Lenin, 1964). Here, Watts attempts to integrate both, construing a differentiated peasantry's "household economy" as "autonomous" until "compromised" by contracts (the "agent" of capitalism).

Yet locating CF as a prime mover of capitalism in "peasant" social formations is conceptually and empirically awkward. It is not clear how, as de Janvry (1981) suggests, CF stands as a distinct "road" to capitalism alongside other accumulation paths from "above" or "below" (Oya, 2012, p. 25). If contracts are taken in an expanded sense-as mercantile instruments introducing or deepening exchange relations-the degree to which they serve as vehicles for capitalist relations' "penetration" is a (non-trivial) question pertaining to earlier epochs in capitalism's world-history. The question of how market relations may or may not inculcate capitalist relations in production is-of course-a long-standing and nuanced debate (Brenner, 1976; Heller, 2011; Post, 1995). 
But if contracts are supposed to "penetrate" contemporary production systems existing outside commodity relations, then Watts' claim is especially dubious. Here Little's (1994, p. 222) observation-that $\mathrm{CF}$ is more likely to emerge where commercial agriculture is already entrenched and processes of differentiation are already under way-is critical. This raises questions of how "Lenin's middle and rich peasants" initially differentiated, and how CF can be isolated as an origin or cause. Indeed, Glover and Kusterer (1990, pp. 140-141) contend that $\mathrm{CF}$ is "as likely to prevent social differentiation as to enhance it". Insofar as CF makes capital and markets accessible to small farmers, it may be the slowest path from "traditional" local markets to commercial agriculture.

Similarly problematic is CF's supposed reflection of a particular sort of global agro-food restructuring. Certainly, the historical record shows that $\mathrm{CF}$ is not a unique expression of globalizing networks of agro-food capitals, as CF schemes have existed in multifarious forms throughout capitalism. They have been directed to both domestic and export markets, and spurred by both domestic and foreign (or multinational) capitals, as well as "developmental" and state institutions (such as the World Bank). Watts, among other RPE theorists, is certainly aware of this, and frequently observes CF's diverse concrete configurations.

The confusion is usually resolved by positing that $\mathrm{CF}$ is a mechanism of "flexible" accumulation: a tool to draw profit from diverse social terrains without necessitating direct dispossession within a shifting international division of labour.

The force of this insight, however, is compromised by the question of how profit is drawn. On the one hand, $\mathrm{CF}$ is portrayed as a mechanism to integrate diverse producers, leading-as suggested above-to their conversion into "propertied proletarians". But, on the other hand (this insight being drawn from wider literatures on industrial outsourcing, such as Sayer \& Walker, 1992; Scott, 1984), CF is portrayed as a mechanism to disperse cost and risk -a means of "balkanizing" labour markets and sidestepping barriers to accumulation in agriculture presented by its prolonged and biologically uneven production processes (Mann \& Dickinson, 1978).

But, ultimately, the problem with Watts' formulation lies with the "peasantness" concept itself-typically construed as social formations premised on production-for-use with only occasional market engagement, or, in some cases, extended to include any farming enterprise not utilizing (or relying on) wage labour (Van der Ploeg, 2013). Watts considers large-scale and highly capitalized "family farms" to be "petty commodity producers" (see below), of which "peasants are clearly a variant" (p. 277)-but does not explicate how they are distinguished.

The central ambiguity is concisely identified by Banaji (2016, p. 421). Watts' construal of CF as an "intensified and formalized method of capitalist control over household production" finds tension with case-study evidence pointing to company preferences for capitalist growers. At a minimum, this indicates that "very different sorts of hierarchies and relations of control and 
subordination seem to be at work" and Banaji acutely notes "we clearly need a brighter line between contract farming as a 'sort of control over and regulation of household labor' (Watts, 1994, 67) and contract farming as a legal and economic relationship between capitals" (emphasis added).

\section{3 | Towards a materialist synthesis}

RPE analyses, most seminally by Little and Watts (1994), have critically demystified CF as a mutually beneficial technical relationship between free agents. But to gain further insights regarding unequal exchange and "market-power", reviving a materialist critique requires locating their application to CF within the relations and dynamics of capitalist production, without recourse to "non-capitalist" relations (as represented by "peasantist" assertions of "autonomy").

In the following, I argue that the contract's management of exchange is as likely to reflect the differential valorization capacities of vertically aligned capitals (including PCPs) as cause them from differential "market-power".

I further argue that the deployment of contracts as levers of 'market-power' is best understood when specifically located within a materialist understanding of capitalist production, rather than merely an arbitrary imposition enabled by given market structures. By this method, the connections between CF's content in surplus appropriation and its contradictory formal tendencies to "integration" and "dispersion" are revealed; CF's diverse concrete configurations can be explicated; and its characterization as a method of "flexible accumulation" given greater depth. Rather than reflecting a world-historical conjuncture, CF's "flexibility" resides in its fungibility to different methods of appropriation under shifting market conditions.

\section{1 | Tracing "peasant subsumation": "Formal subsumption", "real subsumption", and the compulsion of exchange}

It is germane to begin by distinguishing contracts from the production of exchange value itself. While Watts' conception of CF as a form of "peasant subsumation" relates to debates between Lenin and Chayanov on the nature of "peasant" production, the concept's roots extend further back-to Marx's concept of "subsumption" in his economic writings prior to Capital, Volume I.

The most relevant passages concern what Marx called the "subsumption" of capital. These are divided into "formal" and "real" phases in the overall reconstitution of pre-capitalist production along capitalist lines. The "putting-out" system of manufacture was clearly a strong reference point, and much of these sections' content can be found in the completed parts of Capital, Volume $I$ on manufacture and large-scale industry. Nonetheless, in these preliminary arrangements, labour's gradual alienation by primarily economic processes marks a stark and interesting counterpart to the visceral accounts of violent dispossession in Part Eight, on "Primitive accumulation". 
Indeed, the analytical roots of "subsumation" are laid bare most vividly in the Grundrisse (Marx, 1973, p. 510), where Marx's "formal subsumption" of capital first appears under the alternate designation "the original transformation" (p. 503) of (usurer and merchant) money into capital:

The way in which money transforms itself into capital often shows itself quite tangibly in history; e.g. when the merchant induces a number of weavers and spinners, who until then wove and spun as a rural, secondary occupation, to work for him, making their secondary into their chief occupation; but then has them in his power and has brought them under his command as wage labourers. To draw them away from their home towns and to concentrate them in a place of work is a further step. In this simple process it is clear that the capitalist has prepared neither raw material, nor the instrument, nor the means of subsistence for the weaver and the spinner. All that he has done is to restrict them little by little to one kind of work in which they become dependent on selling, on the buyer, the merchant, and ultimately produce only for and through him. He bought their labour originally only by buying their product; as soon as they restrict themselves to the production of this exchange value and thus must directly produce exchange values, must exchange their labour entirely for money in order to survive, then they come under his command, and at the end even the illusion that they sold him products disappears. He buys their labour and takes their property first in the form of the product, and soon after that the instrument as well, or he leaves it to them as sham property in order to reduce his own production costs.-The original historic forms in which capital appears at first sporadically or locally, alongside the old modes of production, while exploding them little by little everywhere, is on one side manufacture proper (not yet the factory); this [manufacture] springs up where mass quantities are produced for export, for the external market-i.e. on the basis of large-scale overland and maritime commerce, in its emporiums like the Italian cities, Constantinople, in the Flemish, Dutch cities, a few Spanish ones, such as Barcelona etc. (emphasis in original)

The similarities with RPE's conception of CF as "subsumation" are striking. The transition from production-for-use to production-for-exchange (notably for export) is mediated by a "buyer" upon whom the producer becomes "dependent". The apparent irrelevance of producers' dispossession, and the characterization of their property as a "sham", is plainly paralleled by RPE's construal of CF as a "flexible" mechanism of "proletarianization without dispossession".

Three elements are key. First, exchange relations bring private, concrete labours into relation with abstract social labour through the commodity-product itself. Second, iterated exchange gradually decomposes the product's value components, distinguishing the costs of "the objective conditions of his [sic] labour (means of production)" from those of "subjective conditions of his [sic] labour (means of subsistence)" (Marx, 1976, p. 1026). Third, as the gradual transition from producing products for use to producing exchange values for money (i.e. as production is commodified) cleaves the cost of labour-power from the value of labour, a "surplus" is distinguished-standing as the difference between the product's value (less means of production) and labour's subsistence-and with it, the transformation of "money" into "capital". 
Capital's "capture" of surplus-and indeed its very ontology as "self-expanding" value-rests on its separation from labour-power. Importantly, here Marx is explicating this as a process of proletarianization, where the wage-form emerges as the capital relation's highest reflection. This does not deny the capital relation's existence in other forms, or subordinate the historical importance of political force, but illustrates its potential emergence from economic relations alone.

Here the problem with RPE's characterization of $\mathrm{CF}$ as a systemic mechanism becomes clear: $\mathrm{CF}$ as "subsumation" lacks clear distinction from Marx's wider explication of transition to capitalist relations; its identity is simply mixed with commodification itself, reducing an entire process of social transformation to a single mechanism. Where $\mathrm{CF}$ is conceptualized as exchange relations' agent (rather than intermediary), prior predominance of production-for-use in pre-capitalist social formations must be posited to maintain consistency-even if capitalist relations of production already clearly exist. 5

In an initially unpublished part of Capital, Volume I, Marx (1976) identifies this transition from production-for-use to production-for-exchange as the "formal subsumption" of capital, to critically distinguish it from the "real subsumption" of capital. It is in this distinction that Watts' oblique references to a "systemic link" between "product and factor markets" undermining the "autonomy" of household labour are clarified; and revealed not to be distinct to $\mathrm{CF}$ at all:

All this notwithstanding, [the formal subsumption of capital] does not in itself imply a fundamental modification in the real nature of the labour process, the actual process of production. On the contrary, the fact is that capital subsumes the labour process as it finds it, that is to say, it takes over an existing labour process, developed by different and more archaic modes of production. And since that is the case it is evident that capital took over an available, established labour process. For example, handicraft, a mode of agriculture corresponding to a small, independent peasant economy. If changes occur in these traditional established labour processes after their takeover by capital, these are nothing but the gradual consequences of that subsumption. The work may become more intensive, its duration may be extended, it may become more continuous or orderly under the eye of the interested capitalist, but in themselves these changes do not affect the character of the actual labour process, the actual mode of working. This stands in striking contrast to the development of a specifically capitalist mode of production (large scale industry etc.); the latter not only transforms the situations of the various agents of production, it also revolutionizes their actual mode of labour and the real nature of the labour process as a whole. It is in contradistinction to this last [mode of labour] that we come to designate as the formal subsumption of labour under capital what we have discussed earlier, viz. the takeover by capital of a mode of labour developed before the

\footnotetext{
${ }^{5}$ There is a consonance here with Banaji's (2010, pp. 4-5) emphasized distinction between "modes of production" ("the relations of production in their totality") and "forms of exploitation" ("the immediate labour process"), and the irreducibility of one to the other (such as mistaking from the presence of slavery that a slave "mode" of production predominates). Banaji (p. 9) observes that if "capitalist relations of production can be based on forms of exploitation that are typically precapitalist, then clearly there is not one ostensibly unique configuration of capital but a series of distinct configurations, forms of the accumulation process, implying other combinations".
} 
emergence of capitalist relations. The latter as a form of compulsion by which surplus-labour is exacted by extending the duration of labour-time-a mode of compulsion not based on personal relations of dominance and dependency, but simply on differing economic functions-this is common to both forms. However, the specifically capitalist mode of production has yet other methods of exacting surplus-value at its disposal ... but given a pre-existing mode of labour, i.e. an established development of the productive power of labour and a mode of labour corresponding to this productive power, surplus value can be created only by lengthening the working day, i.e. by increasing absolute surplus value. In the formal subsumption of labour under capital, this is the sole manner of producing surplus value. (Marx, 1976, p. 1021; emphasis in original; square brackets added)

Under formal subsumption, Marx emphasizes that the peasant's or a handicraft producer's "independence" is unwound from gradual commodification, and not from changes in the physical character of tools, or labour processes. Through an unchanged labour process, only appropriation of absolute surplus value proceeds, through longer working hours or more intense work. No relations of personal dependence or domination are presumed. This process occurs under the "eye of the capitalist" (or contractor), only in so far as she/he personifies capital's "differing economic function". "Autonomy" is not lost from changes in the labour process itself, but from the generalization of the capital-labour relation, independent of specific capitalists or producers.

As capitalist relations generalize, however, labour's "real" subsumption under capital advances through relative surplus appropriation. This proceeds as society's general productive powers develop-and, indeed, transforms the labour process itself as new implements, machinery, inputs, and so on are applied. The general rise in the social productivity of labour effects its proportionate devaluation, in turn requiring individual workers to produce more (or higher-value) commodities to meet their subsistence requirements, and that more capital must be necessarily extended in order to do so:

The social forms of their own labour-both subjectively and objectively-or, in other words, the forms of their own social labour, are utterly independent of the individual workers. Subsumed under capital the workers become components of these social formations, but these social formations do not belong to them and so rise up against them as the forms of capital itself, as if they belonged to capital, as if they arose from it and were integrated within it, in opposition to the isolated labour-power of the workers. And this entire process is progressively intensified as their labour-power is itself modified by these forms to such an extent that it is rendered impotent even when it exists autonomously. In other words its independent productive capacities are destroyed once it finds itself outside the framework of capitalism. And on the other hand, with the development of machinery there is a sense in which the conditions of labour come to dominate labour even technologically and, at the same time, they replace it, suppress it and render it superfluous in its independent forms. (Marx, 1976, p. 1055; emphasis added) 
The point here is that compulsions concomitant with the extension of value relations under formal subsumption are intensified-as a matter of course-under "real" subsumption. The "systemic link" between the "product" and its "factors" does not arise from new technology itself, or direct changes in concrete labour processes, but in the rapid rises in socially average labour productivity accompanying them. For "independent" producers, whether these technologies are contractually disseminated is irrelevant to their welfare (unless either they are sold higher prices than would otherwise pertain, or do not sufficiently raise labour productivity). These pressures concern all scales of producer, but the dejection it confers stands in proportion to producers' ability to meet them. "Small" producers unable to meet ever-rising socially average labour productivity, in relative surplus appropriation, must compensate, in commensurately aggressive fashion, in ever-longer work and/or ever-lower consumption; that is, by absolute appropriation. ${ }^{6}$ The higher socially average labour productivity is, the more acutely this pressure presents itself, particularly where greater land-sizes of average fertility stand as a prerequisite for "lumpy" (non-divisible) means of production. 7 The differential between socially average labour productivity and a producer's concrete capabilities may rise so severely that production-for-sale is rendered impossible. Production-for-use is the only resort, but, even here, producers are stymied by capitalist production's broader advance: as their own production's value diminishes, so does its value in trade. This process advances behind producers' backs, and so entire social formations appear to "rise up" against them. While appearing as consequent to the "contract", it is social labour's wider development that anonymously "suppresses" them.

\section{2 | "Bestowed gratis upon society": Petty commodity producers releasing surplus outside "the contract"}

In summary, then, "independent' producers" "autonomy" is negated, first, by the exchange relationship itself; that is. by bringing private labour into relation with social labour via the price mechanism. It is also negated by the compulsion of producing surplus labour-time consequent to the commodification of subsistence and means of production-processes preceding $\mathrm{CF}$, or underpinning it in some cases. This lack of autonomy is intensified, finally, as the general social productivity of labour rises, effecting the devaluation of labour and the commodity.

Having repudiated the notion that $\mathrm{CF}$ "penetrates" non- or pre-capitalist states of "peasantness", examining CF from a value perspective requires reconceptualizing small-scale production within value relations. Many will recognize this as central to the petty commodity production concept, wherein small producers occupy an inherently (and dynamically) unstable position-under the contradictory pressure to valorize capital and socially reproduce labour- power (Bernstein, 1988; Gibbon \& Neocosmos, 1985). Gibbon and Neocosmos (1985, p. 177) highlight Marx's (1969, p. 408) first elucidation of the concept:

\footnotetext{
${ }^{6}$ That nominally "peasant" producers engage in "drudgery" and "underconsumption" (Van der Ploeg, 2013) is not in contention. Rather, it is the inference both are governed by subjective considerations.

${ }^{7}$ And so the inverse: the lower socially average labour productivity is, the less acutely this pressure manifests. This is often somewhat mischaracterized as concerning a particular crop's "labour-intensity", as are findings that CF works best where crops are "labour intensive". This speaks to the error (e.g. Van der Ploeg, 2013) of construing small-scale producers as "productive" on the basis of value generated per hectare despite extremely low levels of value generated per worker, household or otherwise.
} 
The independent peasant or handicraftsman is cut up into two persons. As owner of the means of production he is capitalist, as labourer he is his own wage-labourer. As capitalist he therefore pays himself his wages and draws his profit on his capital; that is he exploits himself as wage-labourer, and pays himself in the surplus-value, the tribute that labour owes to capital ... the handicraftsman or peasant who produces with his own means of production will either gradually be transformed into a small capitalist who also exploits the labour of others, or he will suffer the loss of his means of production ... and be transformed into a wage-labourer. This is the tendency in the form of society in which the capitalist form of production predominates.

A second important consideration in approaching CF from the PCP vantage is establishing (within value relations) how small farmers persist alongside (and even undermine) their more capitalized peers, and how they can be "squeezed". Put differently, the question is whether an enhanced surplus can be extracted from petty producers-even by extortion (via market-power or otherwise). ${ }^{8}$

Marx (1977, pp. 805-806) addresses the issue directly in relation to exaction of ground rent:

For the peasant owning a parcel, the limit of exploitation is not set by the average profit of capital, in so far as he is a small capitalist; nor on the other hand by the necessity of rent, in so far as he is a landowner. The absolute limit for him as a small capitalist is no more than the wages he pays to himself, after deducting his actual costs. So long as the price of the product covers his wages, he will cultivate his land, and often at wages down to a physical minimum ... The rent anticipated in a price of land and in the interest paid for it can therefore be nothing but a portion of the peasant's capitalised surplus-labour over and above the labour indispensible for his subsistence, without this surplus-labour being realised in a part of the commodity-value equal to the entire average profit, and still less a fixed excess above this average profit in the form of rent ... One portion of the surplus-labour of the peasants, who work under the least favourable conditions, is bestowed gratis upon society and does not enter at all into the creation of value in general. This lower price is consequently a result of the producers' poverty and by no means of their labour productivity.

Here, then, PCPs' (a) persistence by valorizing at a lower rate of profit and (b) this profit's possible appropriation by third parties are premised on restricting "wages" and consumption "to a physical minimum". Some will recognize this as the famous "self-exploitation" thesis favoured by neoclassical and Chayanovian analyses, as well as some early Marxists such as Kautsky (Bernstein, 2010; Griffin, Khan, \& Ickowitz, 2004; Van der Ploeg, 2013).

Importantly, this dynamic is not contingent on contractual extortion, and can occur simply from competitive commodity production. Nonetheless, its durability is highly vulnerable to advances in the social productivity of labour (as demonstrated later). Indeed, although PCPs

${ }^{8}$ This point is critically explored by Starosta (2010) in relation to non-agricultural capitals. 
typically conjure up a "peasant-like" image, as this dynamic pertains to those operating at "socially average" levels of productivity, they can include seemingly large, capital-intensive "owner operated" and "family" farms. Arguably, the large amount of capital that contemporary commercial agriculture requires to meet the "social average" means that such farms would be its chief forebearers.

The principle, and its relevance to contracts as mechanisms to appropriate a surplus, can be illustrated with a simple hypothetical example. Presume that a capitalist and PCP each supply one ton of cash crops from one hectare per season, independently of any particular contracting arrangement. Presume further that they employ the same scale- neutral means of production $(C-$ say, at $\$ 3)$, requiring the same number of workers at the same cost of reproduction ( $V-$ say, \$1 each). Whether this reflects a "high" or "low" level of technological development-that is, whether the PCP is a highly capitalized "family farmer" or "peasant" producer-is, for now, irrelevant (Figure 2).

Now imagine this scenario in two alternative and completely discrete social formations. In the first, a few PCP farmers exist amongst predominately capitalist producers. Consequently, the capitalist farm's average costs constitute the crops' "socially average" value of $\$ 10$. This yields $\$ 3$ for appropriation by capitalist farmers, as well as for PCPs operating at the same level of technological development, but for whom it is empirically indistinguishable from the wage fund.

In the second social formation, however, PCPs predominate, and set the "socially average" price. Now PCPs' capacity to survive at the "physical minimum" suppresses the average price to \$7. Relying solely on the wage fund, PCPs release their erstwhile \$3 surplus; to the landlord, consumer, or-indeed-contractor. Agricultural accumulation is severely constrained, and only possible if PCP and capitalist farmers offer wages below labour's social reproductive costs; that is, "super-exploit" labour via absolute surplus appropriation. For the PCP, this might be extorted by cruel discipline from the family head. For the shrewd capitalist, the lack of profit may impede investment altogether.

This does not preclude "extra" monopolistic/monopsonic relations and "squeezing", or suggest that they exist in strict accordance with movements in value dynamics; only to distinguish these more general tendencies from the contingencies of concrete circumstances. But to the extent that "squeezing" can (and frequently does) occur, it is as a catalyst-while the cause is rooted in generalized relations of commodity production and exchange. This militates against overly functionalist readings of CF, particularly regarding small farmers. While they may be associated with lower wages than other productive forms (Porter \& Phillips-Howard, 1997, p. 234; Sender \& Johnston, 2004, pp. 153-154), this does not mean that contractors capture surplus labour in the form of lower production costs, as implied by Watts (2010). 9 To suppose that CF is introduced in order to capture lower wages, it must be

\footnotetext{
${ }^{9}$ One also cannot assume that CF will always carry lower wages. Li (2011, pp. 288-292), for example, cites an Indonesian palm oil scheme where workers enjoy better conditions on $\mathrm{CF}$ farms than the core plantation.
} 
shown that (i) low (effective) wages translate into lower unit prices under CF than other forms of production, and (ii) the contractor captures these gains.

\section{3 | Contract farming as mechanism of "integration": "Proletarianization without dispossession" and the centralization of capital}

The previous subsection illustrated how, given static technological conditions, dynamics of competition between capitalist farmers and "self-exploiting" PCPs are sufficient to explain the "release" of surplus, and hence stymie capitalist accumulation and investment in agriculture-without reference to any rarefied "pre-" or "non-"capitalist modes or relations of production.

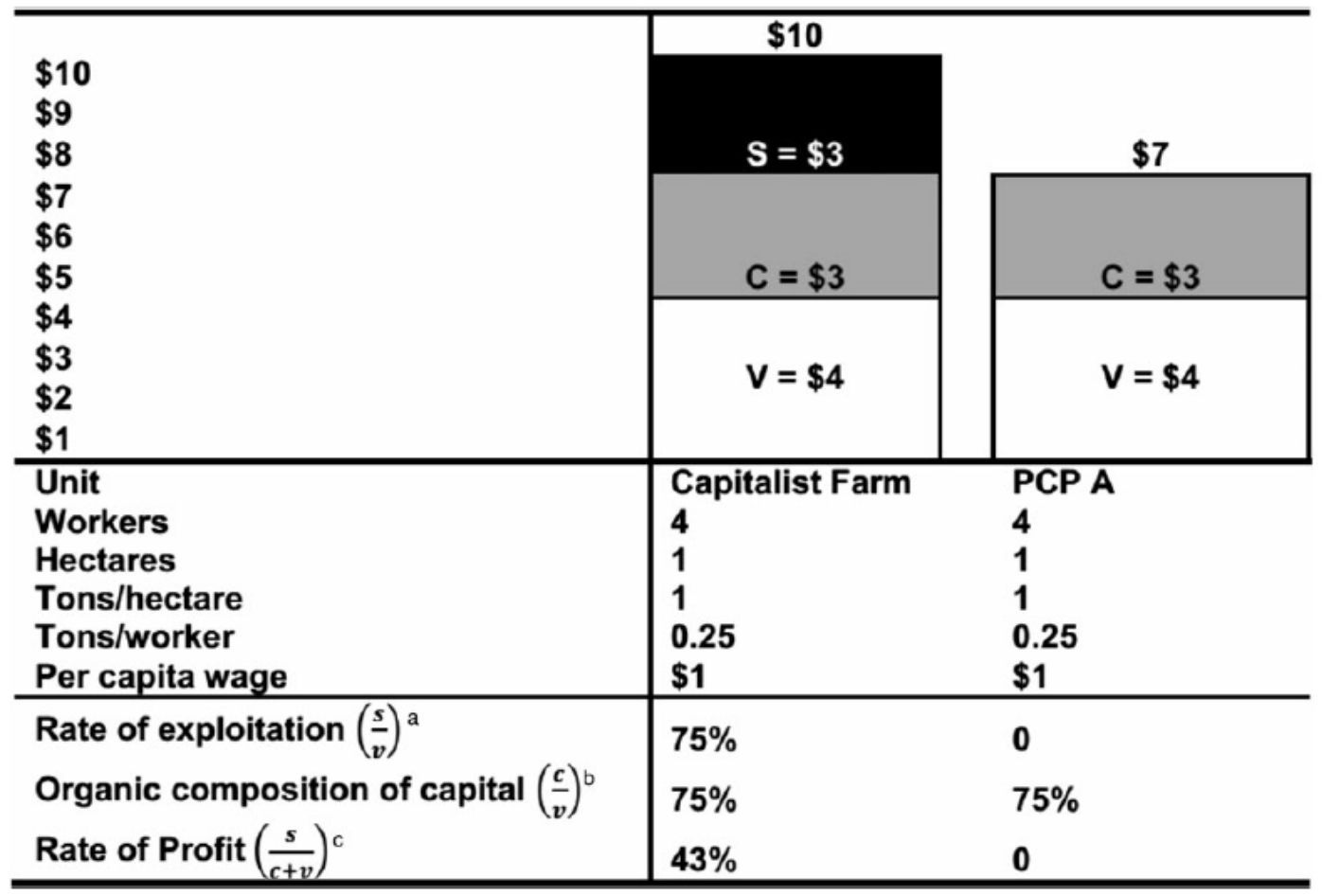

FIGURE 2 An illustration of PCP "self-exploitation" from a value perspective under static technological conditions Notes: 'The rate of exploitation, $s / v$, is a ratio of the value appropriated from labour (s, denoting "surplus") against the value that labour receives to cover its costs of reproduction ( $v$, for its designation by Marx as "variable capital"). The higher the rate of exploitation, all else being equal, the higher is the rate of profit (Fine \& Saad-Filho, 2004, pp. 39-40; Harvey, 2010, pp. 128-131; Marx, 1976, p. 317).

'The organic composition of capital, $c / v$, essentially expresses the capital intensity of a business as a ratio of the value of capital ( $c$, for its designation by Marx as "constant capital") to the value of labour-power ( $v$ ). In contradistinction from the rate of exploitation, a rise in the organic composition lowers the rate of profit, all else being equal. In static contexts, the organic composition is a value expression of the "technical composition of capital", the physical amount of capital against actual amount of (paid) labour. In dynamic contexts, the same ratio is often known as the "value composition of capital", which does not reflect technical composition as such (and would change along with shifts in the value of raw materials, for example) (Fine \& Saad-Filho, 2004, pp. 102-107; Harvey, 2010, pp. 263-267; Marx, 1976, p. 762).

'The rate of profit, $s /(c+v)$, is a ratio of the amount of surplus appropriated from production against investment in labour-power and means of production. It also expresses the ratio of the rate of exploitation against the organic composition of capital, $(s / v) /[(c / v)+1]$, to show that it is enhanced if the former rises, suppressed if the latter rises, and vice versa (Fine \& Saad-Filho, 2004, p. 111; Harvey, 2010, p. 265; Marx, 1977, pp. 211-231). 
This subsection builds upon this model's conditions by introducing monopsonic contractual relations with an industrial processor. It demonstrates how under these conditions CF can, indeed, enable processors to capture surplus released by PCPs, and see their effective "proletarianization without dispossession", in a tendency to integration. In contradistinction from RPE analyses-where the contract is an arbitrary tool of monopsony power-industrial competition is differentially introduced to demonstrate how such power is systemically compelled. This illustrates how $\mathrm{CF}$ can operate as one mechanism in the centralization of capital, and emphasizes the (dialectical?) unity of exchange and production. It is important to reiterate that this represents only one conceptual parameter of CF's potential content, while subsequent sections show how these change under different conditions.

To demonstrate these dynamics, Figure 3 compares two "worlds", distinguished only by the operation of competition. Comprising both are three simple and discrete monopsonic commodity chains under static technological conditions, differentiated only by agro-processing linkages and different dominant forms of agricultural production; that is, whether the "socially average" price is determined by PCP or capitalist producers.

The first chain illustrates a fully vertically integrated agro-processing firm, while in the second and third chains contracts mediate exchange between, respectively, dominant PCP and capitalist suppliers and identical processors. The PCP and capitalist farms maintain their value composition from the previous section, while the processor's total raw material costs $\left(c^{\prime}\right)$ includes $\$ 1$ per ton for transport costs. Above these, processors contend with identical factory $(k)$ and labour $(v)$ costs, each at $\$ 10$ a year. The rate of exploitation $(s / v)$ is held constant at $100 \%$, leading to $\$ 10$ in surplus. The crops' physical transformation into processed commodities is presumed constant, where 5 tons of crops produce 1 ton of processed commodities. ${ }^{1010}$

In "World 1", value relations are impaired by the absence of competition between chains. The differential profitability of identical factories, hence, hinges entirely on the value of raw materials. Here, the link between "self- exploitation" and $\mathrm{CF}$ as a mechanism of "proletarianization without dispossession" is strongest. As before, the PCPs' surplus is alienated by competitive "self-exploitation", retaining only the value of their labour-power and means of production. ${ }^{11}$ As the PCPs capture no surplus, their investment does not valorize. Hence, it is not the PCPs' "capital" at all; the contract has facilitated its centralization in the processor, and CF's appearance as mediating exchange between discrete circuits of production is an illusion. The PCPs are a mere "self-managing branch" in the overall production of the processed commodity, manifest in a virtual "lower" input cost of $\$ 4$ per ton, and enhancing

\footnotetext{
${ }^{10}$ Variation in the contractor-processor's valorization capacities is not illustrated due to space constraints, but is another key factor in CF's content, and is of greater significance the tighter the contractual relationship is. Nonetheless, basically put, the more enhanced the contractor's valorization capacities are in relation to the "social average", the less stridently value dynamics will act as a motive force, and vice versa.

${ }^{11}$ For simplicity's sake, the "value of labour-power" in the models is designated by the cash value of subsistence, but it need not take this form. Some firms may provide products, such as food or inputs for food production, or even services such as healthcare, as part of the effective "wage". Such issues are important in examining any particular scheme, but do not impact the general and abstract line of argument pursued here.
} 
the valorization of the processor's fixed capital (Moore, 2011). Indeed, there is no distinction in value content between the PCP chain and the integrated agro-business, both realizing a 10\% rate of profit. Should capitalist farmers compete at the "socially average" price set by PCPs, they will be disappointed by the evaporation of their surplus.

This dynamic's importance is counterfactually illustrated by the chain supplied by capitalist farmers. In the absence of competing PCPs or monopsony power, the contracting processor must provide terms allowing agricultural capital to valorize. This may, say, be owing to capitalist farmers enjoying alternative production options, with the contractor forced to provide terms meeting the "opportunity cost" of other landed investments (or, perhaps, competing contractors). All else being equal in the industrial capitalist's enterprise, higher raw material costs raise the value composition $\left[\left(c^{\prime}+k\right) / v\right]$ and, hence, the cost of producing the same amount of commodities, from $\$ 110$ to $\$ 140$. Forty per cent of the commodity's value is profit (\$40), but $75 \%$ (\$30) remains in agriculture, leaving the processor with an $8 \%$ rate of profit. ${ }^{12}$

\footnotetext{
12 The same point is observed of capital in general by Harvey (1982, pp. 130-131) in his seminal Limits to capital: "If vertical concentration has the effect of lowering the value composition of capital-always assuming, of course, that the actual production technology remains constant - then it can provide a mechanism that counteracts the supposed 'law of rising organic composition'. Before we get too carried away with this idea, we had better consider certain circumstances that modify it." The most pertinent modifying circumstance for Harvey is turnover time. If variable capital turns over more slowly than constant capital, this can offset the gains of reducing the value composition by vertical integration. Harvey here nonetheless seems to neglect that these may themselves be more than offset by a paired rise in the rate of exploitation. As put by Kay (1975, p. 144): "An increase in relative turnover ... by a fall in the ratio of [turnover time of variable capital: circulating capital] tends to increase the rate of profit insofar as it increases [the rate of exploitation] and reduces it insofar as it brings about a rise in the organic composition of production. But the net effect is always positive for the rate of profit." In either case, this is less of a direct concern for agriculture, owing to the barrier biological processes present to reducing turnover time (Mann \& Dickinson, 1978), considered below.
} 


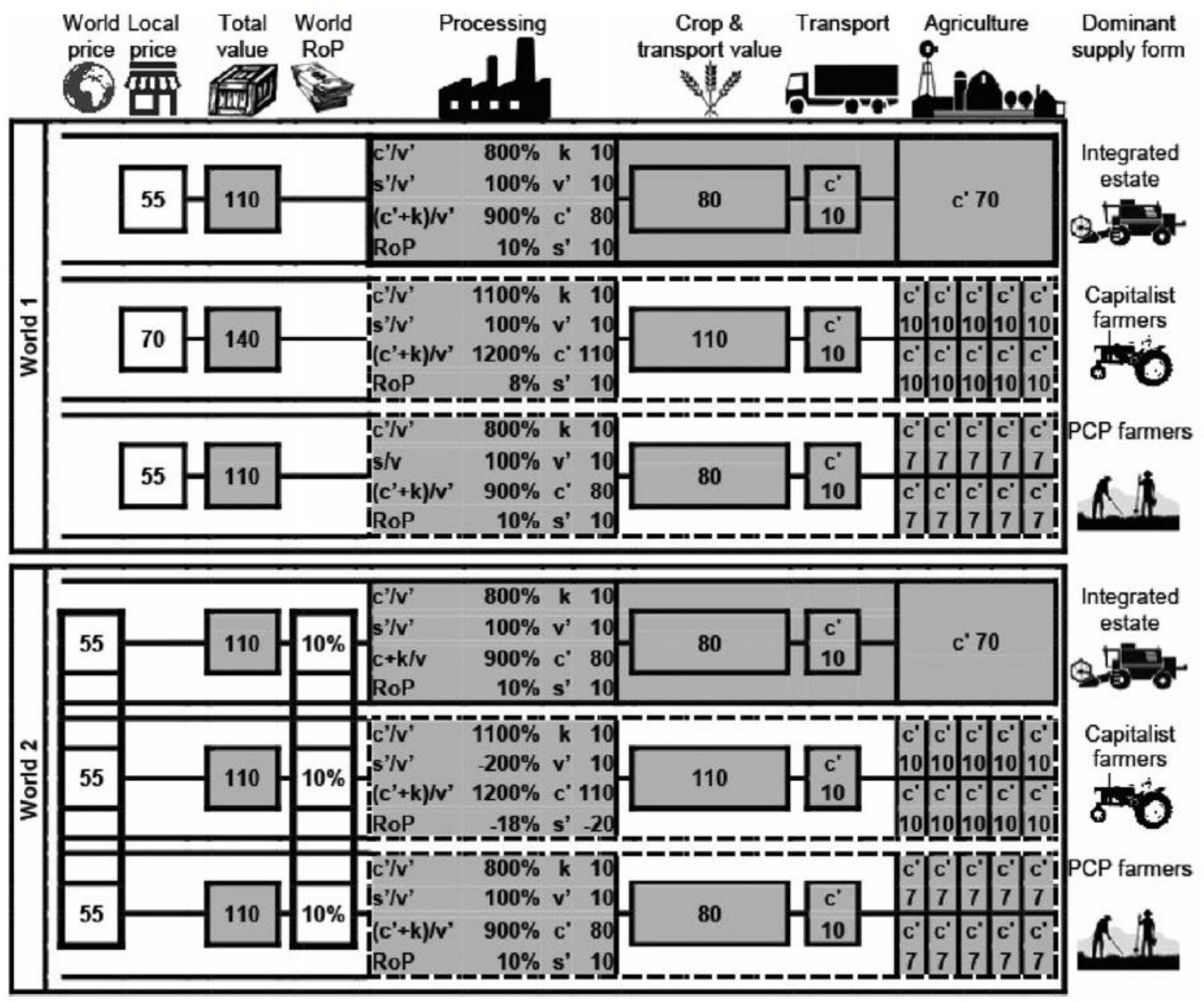

FIGURE 3 An illustration of the dynamics of "self-exploitation" on competition between simple monopsonic commodity chains.

Notes: $c^{\prime}$ refers to the total value of agricultural raw materials (i.e. inclusive of the cost of constant capital (c), variable capital ( $v$ ) and, where applicable, surplus ( $s$ ) within farming), with costs of transport included as a distinct component. $k$ ' denotes the capital costs associated with running the factory in particular, while $v^{\prime}$ and s' concern the cost of variable capital (i.e. the cost of labour-power) and surplus appropriated at the level of processing.

Likewise, $s^{\prime} / v^{\prime},\left(c^{\prime}+k\right) / v^{\prime}$, and RoP refer to the rate of exploitation, the organic composition of capital, and the rate of profit at the factory level. $c^{\prime} / v^{\prime}$ provides the ratio of the cost of raw materials to variable capital, to emphasize the particular impact of changes in the prices of raw materials, in so far as $k$ is held constant throughout the models provided

Should PCPs enter under these conditions, the boon that they enjoy could enable their emergence as capitalist farmers themselves.

In "World 2", monopsonic supply relations still pertain, but competition is introduced in final commodity prices and, as a reinforcing condition, in the average rate of profit. As the integrated and PCP-supplied processors are more price-competitive and afford higher rates of profit (equal to the "world" rate, upon which other concerns, such as loan finance, are premised), new entrants will probably follow these "models" in some combination. Hence, 
these producers' valorization capacities will set the "socially average" price and rate of profit, at $\$ 55$ and $10 \%$, respectively.

But for the industrial firm supplied by capitalist farms, the new "socially average" price of production pushes the enterprise into a $-18 \%$ loss. To break even, the capitalist processor must lower overall costs by $\$ 20$, and a further $\$ 10$ must be "squeezed" to meet the average rate of profit. Varied contractual mechanisms may be employed. For example, the processor may implement a "flexible" pricing formula, tied to the final realized value, to transmit this pressure into lower raw material prices, or perhaps compel the capitalist farm to absorb circulation costs. In any case, the contract serves only as a medium of value relations. However, importantly, here it is capitalist farms being "squeezed" (by the processor's monopsony powers) under indirect but effective competitive pressure.

The "proletarianization" of PCPs that transfixes much thinking about CF here corresponds to a broader process of centralization of capital driven by capitalist competition. The parameters of "victory" between vertically aligned capitals are conditions of survival anonymously defined in "horizontal" competition. Ultimately, either the industrial capitalist "proletarianizes" capitalist farmers such as his competitors, or the capitalist farmer accumulates sufficiently to assume the industrial capitalist's role. Other intermittent, possibly creative, forms are of course possible, such as cooperative ownership. Whatever the outcome of struggle between capitalists, however, the process of centralization continues.

\subsection{The particular impact of technical change in concentrating agricultural capital and "suppressing" petty commodity production}

Thus far, we have examined how PCPs' propensity for self-exploitation competitively inhibits wider accumulation and capitalist investment in agriculture, advancing tendencies to vertical integration, and capital's centralization up and downstream of farming. Here, CF operated less to "proletarianize without dispossessing" PCPs than capitalist farmers. Although CF operated by monopsony power, it was not arbitrary, and proceeded from competitive compulsions in price and investment. Hence, labour-power's alienation from its product resembles Marx's "formal subsumption", from within value relations and without positing prior non-capitalist relations.

Both the contractual and non-contractual models carried two critical operating assumptions. The first was static technological conditions. The second was that all production value was realized in sale. This subsection considers the former, while the next considers the latter.

Before considering how technical change affects $\mathrm{CF}$ in particular, it is worthwhile to again first consider key aspects of its general impact, particularly in concentrating agricultural capital. As intimated by the review of Marx's "real subsumption of capital", a rising social productivity of labour accompanying technical change devalues (here, agricultural) commodities, reducing/annihilating PCPs' surplus, and advancing their impoverishment. 
This can be simply illustrated by modifying the prior example of PCP and capitalist farms from Figure 2 erstwhile competing under static technological conditions. Now presume that-by expanding the scale of production over 2 hectares and introducing new technology-labour productivity on the capitalist farm (possibly a prior PCP) radically increases. Figure 4 illustrates the value consequences of this scenario. Here, only half as many workers are required at the same cost of reproduction $(V=\$ 2)$, utilizing twice as much capital $(C=\$ 6)$, to generate twice the physical output. Labour productivity has quadrupled, while productivity per hectare remains the same. Critically, the value of 1 ton of crops has halved to $5 \$$, and the capitalist farmer receives the same revenue ( $\$ 10$, now resulting from 2 tons of produce).

Under these conditions of technological change, if PCPs set the "socially average" price, the capitalist farmer will garner "super" profits of $\$ 3$ a ton. However, if the technology disseminates and capitalist farmers set a new "socially average" price, a $\$ 1$ surplus is still generated by workers above their "minimum" reproductive requirements.

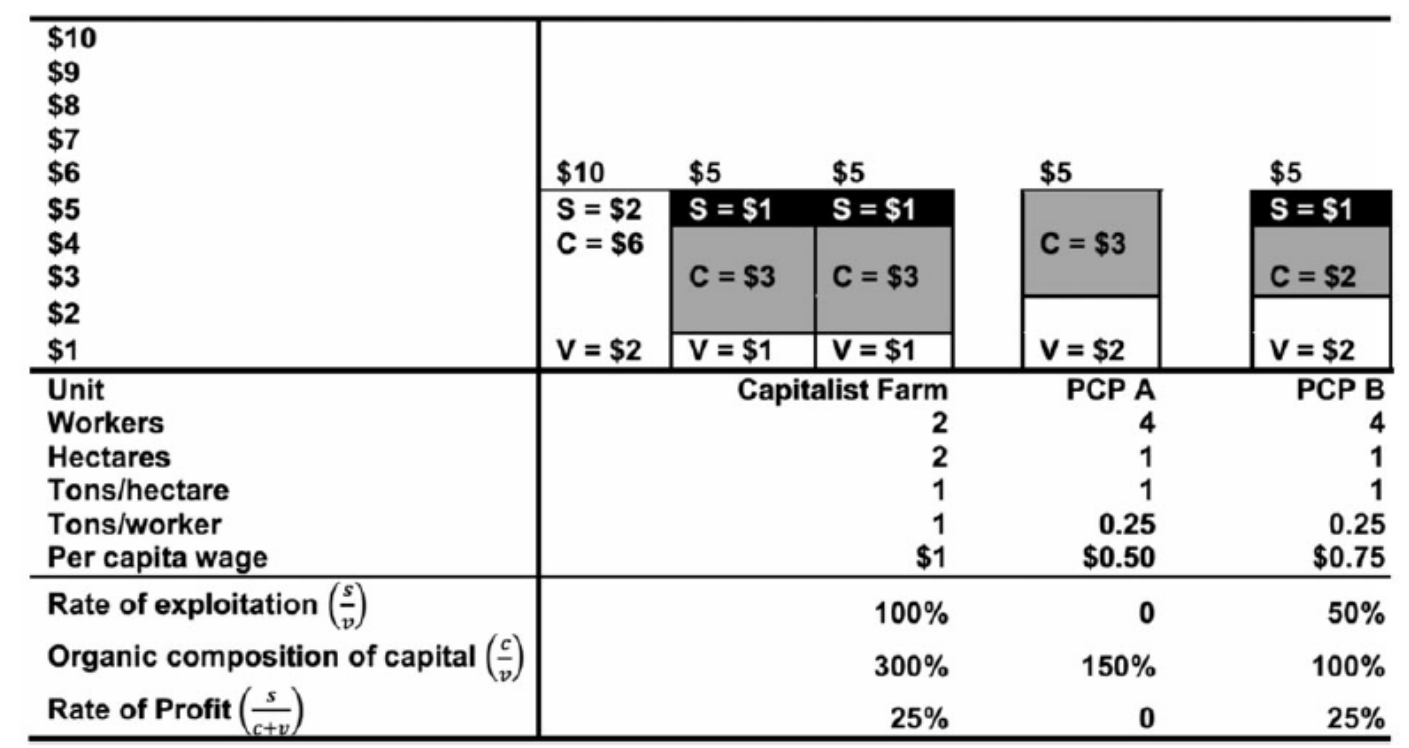

FIGURE 4 An illustration of PCP "self-exploitation" from a value perspective under conditions of technical change

However, for PCPs using "old" methods of production, commercial survival now demands consumption/wages be suppressed to $\$ 2$ ( $\$ 0.50$ a person), without releasing any surplus, and physical survival requires devaluation of their subsistence, or a supplementary income. In other words, the commodity of labour-power itself (Mamdani, 1987) requires devaluation or subsidization, before reinvestment or accumulation can be considered. Even if producers (PCP B) are presumed to enjoy an uncommon differential rent (Fine \& Saad-Filho, 2004), in the form of an "ecological surplus" (Moore, 2011) or "gift" of nature or circumstance (e.g. fertile soils or proximity to the market), the "surplus" garnered (empirically indistinct from the wage fund) may be insufficient to reproduce the PCP household. 
Hence, survival by absolute surplus appropriation or "self-exploitation"-whether due to the compression of "wage" and "surplus" funds, or enabled by a "portfolio" of other economic activities-remains highly vulnerable to commodity devaluation attending rises in socially average labour productivity. This fact may further be disguised by conventional measures of agricultural productivity in yields, as illustrated in Figure 4.

Critically for understanding CF, the PCP's poverty does not guarantee that any "surplus" is released to broader society, the contractor, or other intermediaries. This can be shown by integrating the assumptions of technical change into the prior monopsonic commodity chain model, as illustrated in Figure 5. In "World 3", conditions of competition in final prices and the rate of profit still apply, but processors supplied by contracted capitalist farms predominate, determining the "socially average" price (\$45) and rate of profit (13\%). Clearly, the tendency to integration remains: although an equal surplus is generated by the capitalistfarmer and fully integrated chains, the latter "captures" it entirely to realize an enhanced rate of profit (29\%). All else being equal, investment will flow to this model, driving the centralization of capital.

But most remarkable is the inverted fortunes of the chain supplied by capitalist producers and PCPs. Under open- market conditions, the commodity's devaluation eroded PCPs' capacity to reproduce themselves from "autonomous" commodity production alone. Under contract, this pressure first emerges, or is anticipated, as a $\$ 10$ loss in the industrial capitalist's books, and is transferred via contract, and appears to "rise up" against producers. Possibly, blame is levelled at specified inputs, seemingly "dictating" arduous labour processes, or, as put by Watts, separating production's "conception" from its "execution". Nonetheless, it is neither the contract nor the inputs that "suppress" the producer, but the broader, vigorous, and anonymous transformation of social labour. Indeed, the contractor does not realize any "extra" surplus as before; the $\$ 20$ they must "squeeze" from PCPs only meets wider competitive conditions. This is critical to tempering analyses presuming from contracted PCPs' poverty that "extra" surplus is being released by contractual squeezing, and such squeezing itself to be an arbitrary exertion of "power". 


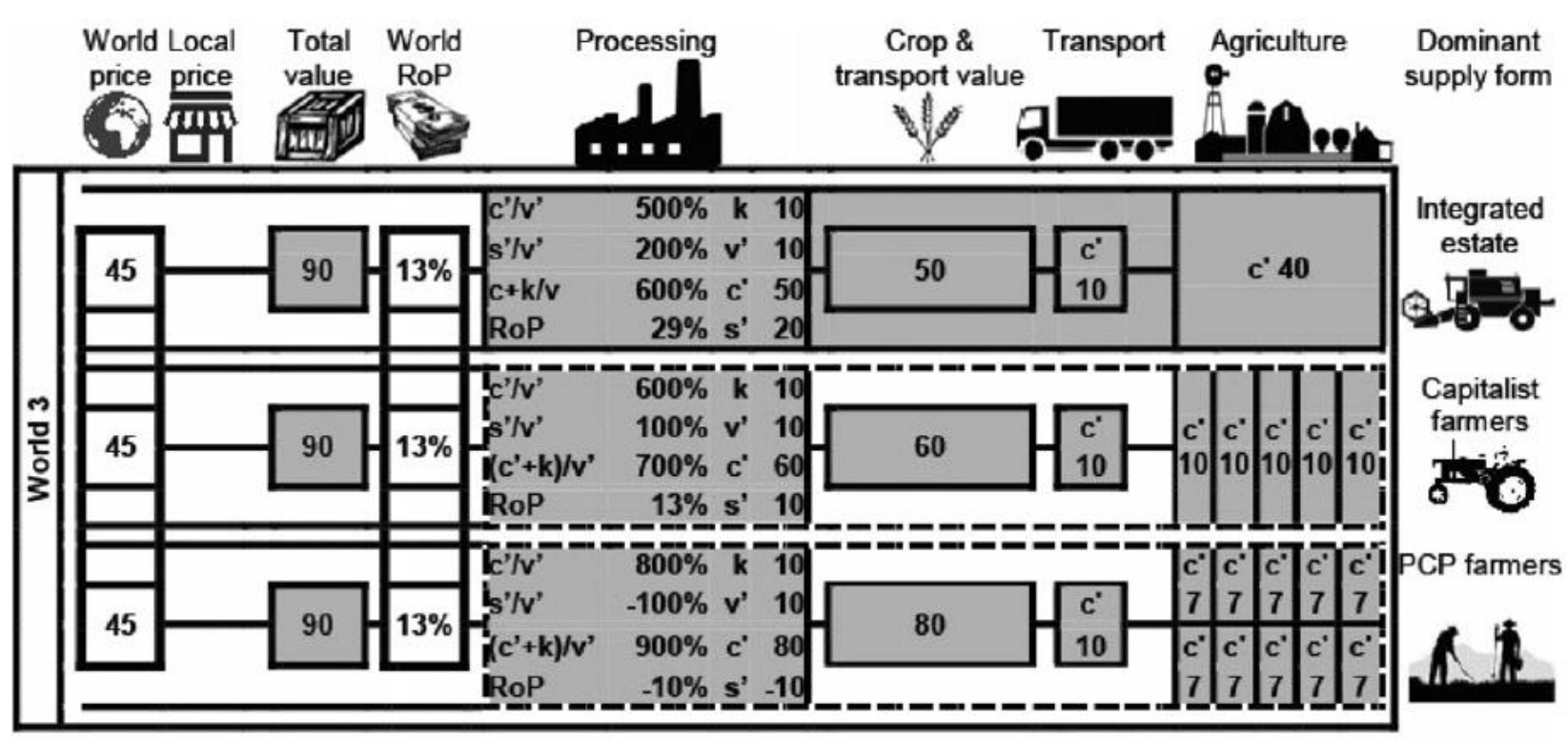

FIGURE 5 An illustration of the dynamics of technical change in agriculture between simple monopsonic commodity chains

CF's role as a medium of technical change in concentrating specifically agricultural capital is also important. It was previously demonstrated how PCPs' capacity for "self-exploitation" could see surplus released for "capture" by contractors, and conditioned wider competition so that this became necessary. Importantly, there is no intrinsic reason for this dynamic to be limited to agriculture. However, for non-agricultural capitals, there remains a possibility that erstwhile "captured" suppliers could drive integration, as they concentrate, centralize, and even innovate. ${ }^{13}$

This does not seem to hold strongly for agriculture. Without resorting to "agrarian exceptionalism" (Araghi, 2003, p. 50), technical change in CF appears distinguished by "farming" as much as "contracts", as technological innovation in agriculture has largely been spurred by (private and public) agencies "outside" farming-transmitted via CF or otherwise. Mann and Dickinson (1978) explain this tendency as consequent to agriculture's peculiar non-identity between production time and labour-time (owing to the former's mediation by biological processes). This inhibits agriculture from raising turnover time through capitalization relative to other sectors, and meeting "socially average" productivity in the wider economy. ${ }^{14}$ This explains why new agricultural technologies focus on "biophysical overrides" (Weis, 2010), and why fixed capital tends to concentrate faster than circulating (input) capital, in turn creating a particular pressure to reduce raw material costs towards diminishing an enterprise's overall value composition (Moore, 2011). In other words, the concentration of agricultural capital is necessary to cheapen raw material prices, but occurs too slowly relative to downstream capital. For the fully integrated agro-business, new

\footnotetext{
${ }^{13}$ Starosta (2010) makes a similar point regarding formerly "captured" garment manufacturers expanding downstream into the domain of "big brand" retailers and designers. Whereas PCPs' bottom limit is the cost of subsistence, the lower valorization limit of "small capitals" is the interest rate on liquidation of their assets.

${ }^{14}$ Prima facie, this appears to be significant to (or a variant of?) Marx's notion of "absolute" ground rent, premised on agriculture's lower organic composition of capital (Fine \& Saad-Filho, 2004; Neocosmos, 1986).
} 
technologies are adopted directly, but for erstwhile "distinct" agricultural capitals, the contract acts as its medium.

This dynamic implicates capitalist farms, but for PCPs there are three avenues for survival. The first, already observed, is "super-exploitation" of the self in under-consumption, others with "starvation" wages, and/or subsidization with other income sources. The second is reproducing production on an expanded scale-that is, accumulation- by acquiring requisite technology to produce at the "socially average level". In the example above, meeting bare subsistence needs requires the PCP adopt the new technology, expand landholdings, and maintain the commitment of atleast two family members to provide enough surplus for the other two previously employed. The PCP, hence, firmly remains a PCP. Intensified exploitation of the self or others is the key to their survival, but no longer places them in the competitive vanguard. Importantly, the contractor's dissemination of new technology may be necessary for such a path, unless otherwise available.

An important caveat applies: PCPs that "successfully" accumulate may later see their surplus "released" and appropriated vis-à-vis self-exploitation, as in the first example, or contractual extortion in sale or input procurement (by debt or otherwise). This gives social differentiation under CF a potentially recursive character. Seemingly "middle" or "large" farmers may not be "capitalist" in so far as their capital does not valorize, or only intermittently so, even if agricultural labour is exploited. ${ }^{15}$

The third option is effective proletarianization. For PCPs that are unable to accumulate, it may be preferable to give contractors direct control over production-at least thereby releasing some labour (whether for school, employment, domestic/use-value or other commodity production, or simply less work). Of course, this requires that (a) they retain direct employment and surplus released as rent (and resist spurious reinvestment beyond the point of declining returns), and (b) subsistence equivalents are not more expensive than wages/rent. In such cases, PCPs stand to engage with contractors as labour-or at best, renters of land.

\section{5 | Contract farming as a mechanism of "dispersion": Shedding the "risk" of unvalorized capital and advancing the concentration of agricultural capital}

The previous subsection examined how a rising social productivity of labour accompanying technical change "suppresses" under-capitalized PCPs, and how their poverty did not guarantee that a surplus was "released" to contractors. Despite appearing as an artefact of CF (or inputs specified under it), the true impetus originated in capitalist commodity production's general compulsions.

\footnotetext{
${ }^{15}$ Just as it is presumptuous to assume distinct "peasant" relations of production from the presence of family-labour or consumption of production, we should caution against presuming that specifically agricultural capital is being valorized from exploited wage-labour. This cautions against too simplistic a view of Bernstein's (2010, p. 94) observation that "'farmers' cannot be 'exploited' by the corporations they contract with or the banks they borrow from (even though they often claim they are!); rather, they exploit the workers they employ".
} 
Although a tendency to integration persisted, technical change saw capitalist producers outcompete PCPs, accentuating the instability of the latter's dynamic combination of capital and labour, and intensifying the forces of their social differentiation. But as the fully vertically integrated agro-industrial business remained most competitive, $\mathrm{CF}$ continued to act as an integrating mechanism to approach this form and "proletarianize" PCP and capitalist farmers.

Here, contrastingly, it is shown how this logic is disrupted by removing assumptions of guaranteed sale and simulating a market contraction. Rather than an integrating mechanism to centralize capital and engage agricultural producers as labour, CF inversely emerges as a mechanism of dispersion to "shed" unvalorized capital (here, agricultural raw material). In this polar tendency, CF instead emerges as a "tool of differentiation" of agricultural capital-now faced with absorbing the cost of unrealized investment. Again, monopsony powers are presumed to be competitively compelled, and not arbitrarily imposed, while the introduction of changing market conditions strengthens and demonstrates the unity of spheres of exchange and production. This dynamic's essential logic is expressed neatly by Wallerstein and Hopkins (1994, pp. 19-20):

Cyclical shifts are thus one of the key considerations in the construction of commodity chains. They are basically the direct reflection of the organizing contradictions of the capitalist development of productive forces. For example, two system-imposed concerns of entrepreneursthe reduction of transaction costs and the reduction of labour costs-commonly require quite opposite changes in social organization and geographical location. In general, transaction costs are reduced through the vertical integration and geographical convergence of boxes of a chain (both worldwide concentration and local urbanization). Labour costs, however, are generally reduced through subcontracting (adding boxes, the opposite of vertical integration) and geographical dispersion of a chain's boxes (both worldwide, and locally ruralisation). So far, it would seem, reduction of transaction costs has taken priority over the reduction of labour costs in A-periods [of expansion], while in B-periods [of contraction] the converse has been true ${ }^{16}$.

\footnotetext{
${ }^{16}$ Again, Harvey (1982, p. 132) recasts the issue in terms of turnover time: "The splitting of a production process into many different phases and firms linked through market exchange appears to be highly desirable, since it diminishes the turnover time of capital. For this reason, even large corporations prefer to sub-contract a lot of production to small firms with shorter turnover times. But the effect of this, as we have seen, is to increase the value composition of capital independently of any changes that may be instituted with respect to the production process."
} 


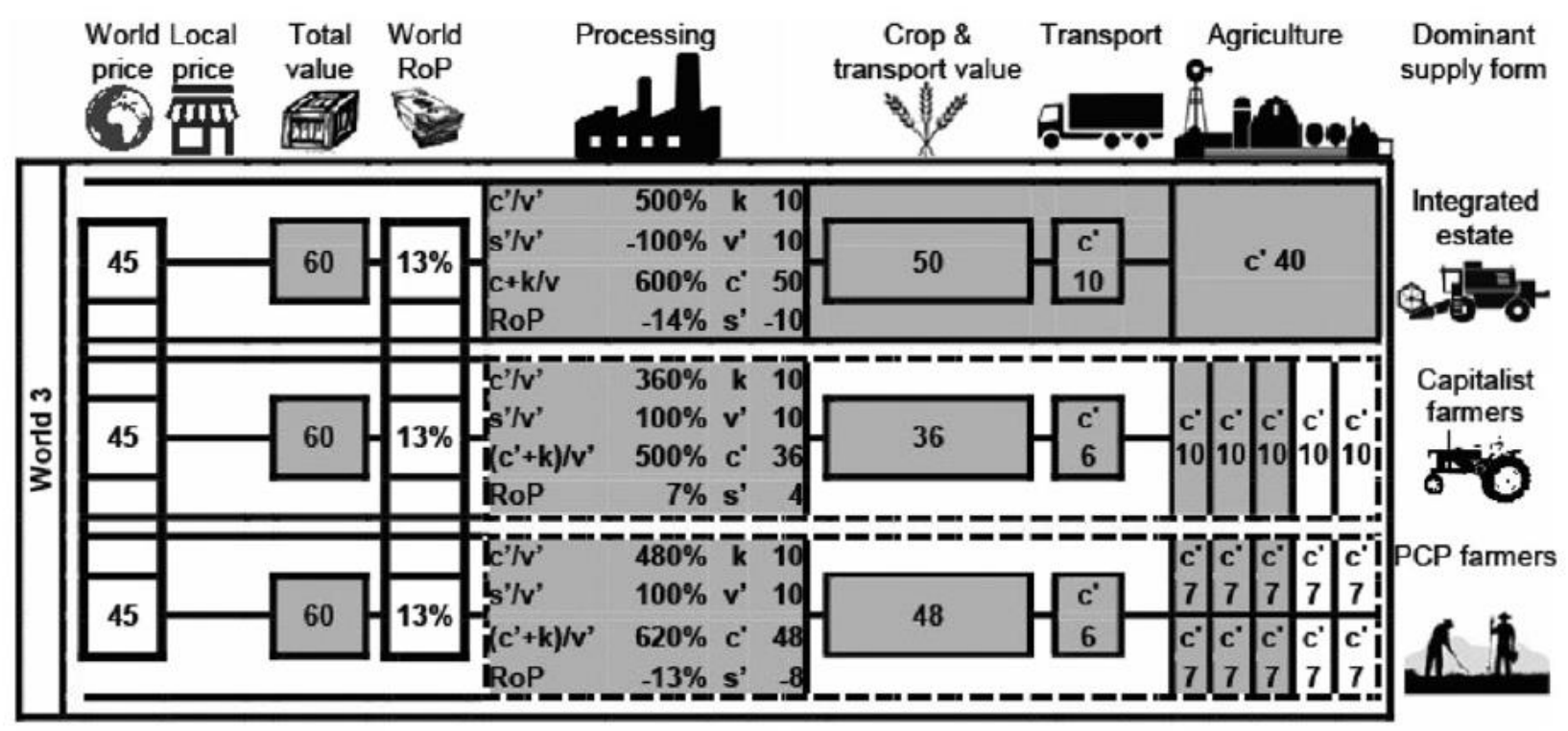

FIGURE 6 An illustration of the dynamics of market contraction between simple monopsonic commodity chains

This suggestion of a profit-centred theory of "power" and shifting market structures ("changes in social organization"), rather than a market-structure theory of profitability common to GVC and NIE analyses, has clear relevance to the conceptualization of CF advanced here. ${ }^{17}$

First, the observation that dynamics of "integration" to reduce transaction costs and improve productivity tend to occur in periods of "expansion" finds clear parallel with the tendency towards the centralization of capital proposed thus far.

Here, I propose one further modification to accentuate the consonance: under capitalism, productivity increases and reducing "transaction costs" amount to "reducing labour costs" through relative surplus appropriation, advanced by Marx. Hence, "reducing labour costs" can be joined with its parallel, augmenting absolute surplus. This is achieved directly by lowering real wages or extending working time, but also indirectly by shifting costs of unvalorized capital and augmenting relative claims to surplus value.

The stylized correspondence of this second tendency with periods of contraction can be demonstrated by a final modification to the simple commodity chain, illustrated by "World 4 " in Figure 6. So far, all models have assumed guaranteed realization in sale; essentially presuming an unlimited market expansion akin to Wallerstein and Hopkins' "A-phase". Now, to simulate a "B-phase", we presume that demand contracts by one third and that only two thirds of production is realized in exchange.

\footnotetext{
${ }^{17}$ Somewhat ironically, this paper was published in a seminal volume of commodity-chain analyses, with questions of power as "governance" arising in response to lacunae in profit-based approaches. Starosta (2010, p. 448) offers one of the strongest statements for reviving a materialist reinversion of the market structure $\rightarrow$ power $\rightarrow$ profit formula implicit in GVC: "[P]ower relations among individual capitals are not, as GCC analysts would have it, the cause of their differential valorization capacities. It is the other way round: because the law regulating the competition process - the formation of the general rate of profit - takes concrete shape through the differentiation of the concrete valorization capacities of each kind of individual capital, the indirect social nexus among the latter is expressed through unequal or hierarchical relations."
} 
The result of this exercise sees an inversion of the "fully integrated" producer's fortunes. Previously the pinnacle of profitability, it now suffers the greatest loss. The central reason is clear: market contraction cannot be mitigated by reducing committed capital investment, particularly agricultural costs "fixed" in the earth. If the interim commodity is perishable, necessary processing before storage even prevents forestalling industrial production. Now it is the more "dispersed" contractor of capitalist farms who triumphs. Simply by reducing raw material purchases from supplier-farmers by two thirds, only a modest reduction in profit is endured, even without reducing ether prices for remaining capitalist farmers or factory wages. The farmer alone is burdened by unvalorized capital; to commercially survive, she/he must weather sunk costs such as inputs, wage advances, and necessary articles of consumption (a dynamic that may be slowed, however, if competing contractors are present). Moreover, if the industrial capitalist alienates even half of capitalist farmers' surplus further, say, by using monopsony power to force farmers to absorb some costs of circulation, their rate of profit would exceed the presumed "World" average. Indeed, even the processor contracting with PCP farmers using the "old" methods loses less than the fully integrated capitalist, albeit only marginally.

It is important to emphasize that this shift in CF's content did not necessitate a change in form, and cannot be deduced by its impact on producers. Both here and in the previous section, the latest inputs were contractually disseminated (whether advanced by cash, credit, or against the crop's value), and saw the concentration of agricultural capital. However, previously, agricultural producers' social differentiation came as a by-product of wider advances in the social productivity of labour, while here the contract specifically served as a "tool of differentiation" to enhance the contractor's valorization.

\section{6 | Rethinking the "flexibility" of "flexible accumulation" in contract farming}

Near the close of "Life under contract", the first chapter in (the seminal) Living under contract, Watts (1994, p. 71) cites Berger (1980, p. 136) to proffer that capitalism's "nature" is "not to create a homogeneous social and economic system but to draw profit from the diversity and inequality that remain in permanence". The comment encapsulates both the power and limitations of Watts' approach to CF. On the one hand, it expresses CF's "diversity" across varied social formations (comprising uneven "configurations of state, capital, and small-scale commodity production") and contests its construal as a "free" or mutual institution.

But in an effort to challenge "essentialist views of agrarian capital-labour relations" (p. 71), Watts inadvertently advances a reductionist and particularistic vision of them. ${ }^{18}$ By

\footnotetext{
${ }^{18}$ Gibbon and Neocosmos (1985, pp. 168-169) concisely refute the supposed 'essentialist' character of the capital-labour relation: "The relationship between phenomena and their conditions of existence - the contradiction between capital and wage-labor-is not an essentialist one because the former are not expressions of the latter (hence their production must be explained), and because the latter do not exist independently of the former ... What makes enterprises, and more generally social formations, capitalist or not, is not their supposed essential features, but the relations which structurally and historically explain their existence. Thus in order to show the capitalist character of African social formations it is not necessary to find sociological categories of capitalists or 'potential capitalists,' wage-laborers or 'wage-labor equivalents.' What has to be shown in order to 'prove' the capitalist nature of such social formations is that that social entities and differences which form the social division of labor in such formations are only explicable in terms of the wage-labor capital relation."
} 
construing "peasants" outside "capital-labour relations", small producers' form of production (or perhaps, their labour process) is conceptually collapsed with their conditions of existence, existing trans-historically "in permanence". Echoing "articulationist" notions, CF emerges as an agent for capital to "flexibly" "subsume" forms somehow constituted outside itself. This ironically both obfuscates the mechanisms by which "profit is drawn" under CF, and reduces attempts to capture CF's very diversity to formulating "ideal types" and "freezing of contingent patterns" (Sayer, 1992)-such as Watt's (pp. 94-96) discernment of "centralized nucleus estate", "transnational corporate", and "smallholder grower" contracting models. By failing to distinguish CF from capitalism's general processes and dynamics (commodification, social differentiation, alienation, etc.), the collapse of form and conditions is replicated at a higher level of synthesis, where $\mathrm{CF}$ expresses its own conditions for existence as a "neo-Fordist" form of 'flexible' agro-restructuring.

Yet approaches to $\mathrm{CF}$ that do not directly incorporate (or, at least, stress) relations of production have also been limited. While skirting problems of non-capitalist forms, capitallabour relations fade into obscurity, or are outright erased, encouraging a problematic dualism between "market" and "production" that cannot be clearly bridged. Insights concerning CF"s differential adaption to, or deployment within, "market structures" are hobbled by the absence of robust explanations for these structures, and their reproduction and/or transformation. Elaborations of various associated characteristics only beg the question of how they emerge as qualities at all. Instead of collapsing form and conditions, the latter are left unexplained, or treated as "natural", given, and/or exogenous. Whether CF is understood as a market-optimizing institution, or reflects the caprice of "market-power", the biggest consequent problem for such analyses is their stasis.

The analysis that I have presented offers a different perspective on CF's "flexibility". By focusing on explicating $\mathrm{CF}$ from within value relations, I have argued that CF's apparent flexibility amounts to more than a diversity of forms adapted to diverse market or social conditions, instead resting in its differential and potentially contradictory content, which can, moreover, change over time. By distinguishing dynamics of capitalist production from "market-power" in exchange, both can be conceptually recombined as a dynamic unity, and CF's relevance to broader processes of surplus appropriation identified. Far from "essentializing" $\mathrm{CF}$, the vantage of a value-analytic reveals that CF's mechanisms and its impacts can only be understood when situated within a wider field of contingent relations. Put differently, this is not a matter of distilling what CF "is", but establishing its parameters to inform examinations of what it does, when it does it, and why.

This tempers, and in some respects, deepens, questions of CF's relation to historical moments of "agro-industrial restructuring". It shows why theorizing CF by seeking regularities of association with formal characteristics (e.g. its juridical-legal constitution) and various "outcomes" (e.g. farmers' relative welfare) can be highly misleading. This is first because dynamic processes such as social differentiation and agricultural concentration are based in relations deeper and wider than CF. Just as CF's identity should not be mixed with broader processes of commodification, nor should CF's form be confused with its mediation of the 
"dull compulsion" of exchange relations within the "whirlpool" of world or international markets-a force as (if not more) powerful today than in Marx's time. ${ }^{19}$ Second, such outcomes can be consistent across the different, even contradictory, ways in which CF is employed as a mechanism of surplus appropriation, if at all.

In this sense, the contention of RPE analysts such as Watts-that CF represents a "neo-Fordist" form of "flexible" agro-restructuring-may be correct, but is incomplete in its analytical depth. $\mathrm{CF}^{\prime}$ s use is not as a lever of accumulation particular to a period (or conjunctural form) of capitalism requiring "flexibility"; rather, it is a form that is "flexible" to different mechanisms of accumulation under shifting conditions. As summarized in Table 3, on one stylized pole stands a tendency to integration and relative surplus appropriation attending periods of expansion, wherein the contract engages producers as labour. On the other is a tendency towards absolute surplus appropriation in periods of contraction, where, conversely, the producer is engaged as a distinct circuit of capital. The PCP's very importance, as a form expressing a dynamic (and unstable) unity of the capital-labour relation, is its fungibility to both tendencies.

Several final caveats are worth noting. First, these poles represent differences in a dynamic relationship-not mutually exclusive forms. There is no necessary reason, for instance, why relative surplus appropriation, say, by specifying use of the technology, may not be married with absolute surplus appropriation, say, by specifying their use beyond the point of declining returns while holding the full cost and risk of failure. The debt relation in particular offers a common mechanism that is "flexible" to both "integration" (by appropriating surplus as interest) and dispersion (by evading the cost of unvalorized capital) that can operate simultaneously.

TABLE 3 Poles of contract farming's content

\begin{tabular}{|c|c|c|}
\hline & Integration & Dispersion \\
\hline Form & "Fewer boxes" & "More boxes" \\
\hline Dominant type of appropriation & Relative surplus & Absolute surplus \\
\hline Methods & $\begin{array}{l}\text { Raising productivity } \\
\text { - Economies of scale } \\
\text { - Reduced transaction costs/cooperation } \\
\text { - Technological innovation } \\
\text { - Breaking tariff/non-tariff barriers } \\
\text { to equal exchange }\end{array}$ & $\begin{array}{l}\text { Reducing labour costs } \\
\text { - Reducing wages } \\
\text { - Shedding "risk" of valorization in } \\
\text { marketing and production } \\
\text { - Erecting tariff/non-tariff barriers } \\
\text { to equal exchange }\end{array}$ \\
\hline Social tendency & "Tool of proletarianization" & "Tool of differentiation" \\
\hline Conditions & Market expansion ("certainty") & Market contraction ("uncertainty") \\
\hline
\end{tabular}

\footnotetext{
${ }^{19}$ One of Marx's (1976, p. 345) explicit remarks on this dynamic is on intensified absolute surplus extraction in American slavery: "But as soon as people, whose production still moves within the lower forms of slave-labour, corvée-labour, etc. are drawn into the whirlpool of an international market dominated by the capitalist mode of production, whereby the sale of their products for export develops into their principal interest, the civilised horrors of over-work are grafted on the barbaric horrors of slavery, serfdom, etc. ... [In the southern states of the American Union] the over-working of the Negro [sic] and sometimes the consumption of his life in seven years of labour became a factor in a calculated and calculating system. It was no longer a question of obtaining from him a certain quantity of useful products, but rather of the production of surplus-value itself." Nonetheless the "dull compulsion" can be as potent as the incarnate Master, as powerfully expressed in the testimony of a Tanzanian tea grower cited by Watts (1994, p. 64): "[CF farm-work] is the big slavery! Work has no boundaries, it is endless!"
} 
It is also necessary to distinguish particular capitals' valorization from chains as a whole. For the sake of simplicity in exposition and illustration, I have presented CF assuming that all variation in processing capitals' valorization occurred from agricultural supply. Such a presumption is untenable in investigating particular chains, even though factory production may appear less differentiated than uneven agricultural conditions. Nonetheless, this cannot be established by simply investigating contractual terms of a single a vertical "slice".

Similarly, for expositive ease, I have assumed that production was orientated to an undifferentiated market. In concrete circumstances, unevenness in national and international markets and politics of market segmentation provide the possibility that particular chains experience conditions that deviate substantially from broader tendencies. For instance, general conditions of market saturation for a particular commodity might prompt contraction and "dispersion" for most, while some enjoying preferential access to a protected market might undergo dynamics of integration. The politics of "flex crop" production (Borras, Franco, Isakson, Levidow, \& Vervest, 2016), whether as a sort of arbitrage or "surplus" absorption, are of particular and complicating importance in this regard.

\section{4 | Conclusion}

This paper has argued that despite divergent political evaluations of CF by different theoretical schools (whether from neoclassical economics or RPE), their conceptualizations of CF's actual mechanisms bear a close consonance with one another. This is particularly true of questions of "power", often understood in terms of market-power-a trend that does not transcend a Liberal market-paradigmatic. Attempts to centre relations in production, most seminally by Little and Watts (1994), have provided a key advance for the radical critique of $\mathrm{CF}$ as a technical institution, but remain hobbled by a rarefied "peasantist" analysis, leadingproblematically-to extrapolations of historical conjuncture ("road to capitalism"; "post-Fordism") from contradictory social impacts ("tool of 'proletarianization"/ "differentiation”).

I have instead argued that a materialist approach offers a firmer ground to anchor CF's relationship to production in synthesis with market dynamics (the focus of Liberal approaches). I have first argued that contracts must be distinguished from capitalist commodity production's implicit compulsions, and showed that the idea that CF "penetrates" "autonomous" peasant farming mirrors Marx's wider concept of "formal subsumption" under capital. The central insight there, that capitalist relations do not necessitate changes in actual labour processes, but tend to intensify for absolute surplus appropriation, is, however, undermined by the idea that contracts bring about these relations and control production. Marx's second "real subsumption" of capital was discussed to show how technological change subverts the "autonomy" of own-production by devaluing commodities themselves-that is, relative surplus appropriation. By these lights, I have suggested that contract farmers' poverty is not sufficient evidence to show they are being abnormally "squeezed", as opposed to simply valorizing at a lower rate of profit-but either scenario is only possible in so far as their commercial survival is governed by meeting a subsistence equivalent. Yet this 
equivalent remains highly vulnerable to technical change, requiring either accumulation, or a growing dependence on other sources of subsistence to satisfy it.

The second main argument has posited that CF's "flexibility" concerns not only its deployment across diverse social contexts for accumulation, but also its diverse content. I have argued that CF encompasses strategies spanning between two poles: on the one side of the spectrum, labour costs, particularly the risk of unvalorized capital, could be dispersed in a manner similar to subcontracting generally (and bearing a correspondence with absolute surplus appropriation); while on the other side, CF could also be used to advance capital's centralization as an integrating mechanism, to raise productivity through economies of scale of various kinds, and encourage relative surplus appropriation. Finally, I have suggested that strategies based on absolute surplus appropriation would tend to be pursued under conditions of contraction, while those premised on relative surplus value are more likely to be pursued in conditions of expansion. Instead of representing the "coming" of capital or capitalism, or a marking of a particularly new period of it, this formulation posits CF as a form adaptable to both conditions, and fungible to shifting emphasis over time.

\section{Acknowledgements}

I am grateful to the many colleagues who have provided critical inputs into the contents of this paper in discussion and presentation. Special thanks are reserved for Emeritus Professor Henry Bernstein for the ever-insightful comments he provided in an earlier draft, and particularly to Professor Ben Cousins for his vigorous encouragement, critical insights, and assiduous review throughout the paper's many iterations.

\section{ORCID}

Alex Dubb http://orcid.org/o0oo-0003-3625-1322 


\section{References}

Araghi, F. (2003). Food regimes and the production of value: Some methodological issues. The Journal of Peasant Studies, 30(2), 41-70.

Banaji, J. (2010). Theory and history: Essays on modes of production and exploitation. Boston: Brill.

Banaji, J. (2016). Merchant capitalism, peasant households and industrial accumulation: Integration of a model. Journal of Agrarian Change, 16(3), 410-431.

Berger, S. (1980). Discontinuity in the politics of industrialized society. In S. Berger \& M. Piore (Eds.), Dualism and discontinuity in industrial societies (pp. 129-141). Cambridge: Cambridge University Press.

Bernstein, H. (1988). Capitalism and petty-bourgeois production: Class relations and divisions of labour. The Journal of Peasant Studies, 15(2), 259-271.

Bernstein, H. (2009). V. I. Lenin and A. V. Chayanov: Looking back, looking forward. The Journal of Peasant Studies, 36(1), 55-81.

Bernstein, H. (2010). Class dynamics of agrarian change. In Halifax, NS: Fernwood/Sterling. VA: Kumarian Press.

Binswanger, H., \& Rosenzweig, M. R. (1986). Behavioural and material determinants of production relations in agriculture. The Journal of Development Studies, 22(3), 503539.

Borras, S. M., Franco, J. C., Isakson, S. R., Levidow, L., \& Vervest, P. (2016). The rise of flex crops and commodities: Implications for research. The Journal of Peasant Studies, 43(1), 93-115.

Braverman, H. (1974). Labour and monopoly capital: The degradation of work in the twentieth century. New York: Monthly Review Press.

Brenner, R. (1976). Agrarian class structure and economic development in pre-industrial Europe. Past and Present, 70, 30-35.

Chayanov, A. V. (1966). In D. Thorner, B. Kerblay, \& R. E. F. Smith (Eds.), The theory of peasant economy. Homewood, IL: Irwin.

Coase, R. (1937). The nature of the firm. Economica, New Series, 4(16), 386-405.

De Janvry, A. (1981). The agrarian question and reformism in Latin America. Baltimore, MD: Johns Hopkins University Press.

Fine, B., \& Saad-Filho, A. (2004). Marx's capital. London: Pluto Press.

Gereffi, G., Humphrey, J., \& Sturgeon, T. (2005). The governance of global value chains. Review of International Political Economy, 12(1), 78-104.

Gibbon, P., Bair, J., \& Ponte, S. (2008). Governing global value chains: An introduction. Economy and Society, 37(3), 315-338.

Gibbon, P., \& Neocosmos, M. (1985). Some problems in the political economy of "African socialism". In H. Bernstein, \& B. Campbell (Eds.), Contradictions of accumulation in Africa: Studies in economy and state (pp. 153-205). London: SAGE Publications.

Glover, D., \& Kusterer, K. (1990). Small farmers, big business: Contract farming and rural development. London: Macmillan.

Goodman, D., \& Watts, M. (1994). Reconfiguring the rural or fording the divide? Capitalist restructuring and the global agro- food system. The Journal of Peasant Studies, 22(1), 149. 
Griffin, K., Khan, A. R., \& Ickowitz, A. (2004). In defence of neo-classical neo-populism. Journal of Agrarian Change, 4(3), 361-386.

Grosh, B. (1994). Contract farming in Africa: An application of the New Institutional Economics. Journal of African Economies, 3(2), 231-261.

Hamilton, N. D. (2008). Agricultural contracting: A U.S. perspective and issues for India to consider. In A. Gulat, P. K. Joshi, \& M. Landes (Eds.), Contract farming in India: A resource book. Retrieved from http://curis.ku.dk/ws/files/41824775/Prowse_2012_Contract_farming_in_developing_c ountries_AFD_A_Savoir_Paper_12.pdf

Harvey, D. (1982). The limits to capital. Oxford: Basil Blackwell.

Heller, H. (2011). The birth of capitalism: A 21st century perspective. London: Pluto Press. Kay, G. (1975). Development \& underdevelopment: A Marxist analysis. London: Macmillan.

Kirsten, J. F., Karaan, A. S. M., \& Dorward, A. R. (2009). Introduction to the economics of institutions. In J. F. Kirsten, A. R.

Dorward, C. Poulton, \& N. Vink (Eds.), Institutional economics perspectives on African agricultural development (pp. 1-34). Washington, DC: International Food Policy Research Institute.

Lenin, V. I. (1964). The development of capitalism in Russia: The process of the formation of a home market for large-scale industry. In Collected works (Vol. 3). Moscow: Progress Publishers.

Li, T. (2011). Centering labor in the land grab debate. The Journal of Peasant Studies, 38(2), 281-298.

Little, P. (1994). Contract farming and the development question. In P. Little, \& M. Watts (Eds.), Living under contract: Contract farming and agrarian transformation in sub-Saharan Africa. Madison, WI: University of Wisconsin Press.

Little, P., \& Watts, M. (1994). Introduction. In P. Little, \& M. Watts (Eds.), Living under contract: Contract farming and agrarian transformation in sub-Saharan Africa (pp. 320). Madison, WI: University of Wisconsin Press.

Mamdani, M. (1987). Extreme but not exceptional: Towards an analysis of the agrarian question in Uganda. The Journal of Peasant Studies, 14(2), 191-225.

Mann, S. A., \& Dickinson, J. M. (1978). Obstacles to the development of a capitalist agriculture. The Journal of Peasant Studies, 5(4), 466-481.

Marx, K. (1969). Theories of surplus value: Part I. Moscow: Progress Publishers.

Marx, K. (1973). Grundrisse. London: Penguin.

Marx, K. (1976). Capital, Volume I. London: Penguin.

Marx, K. (1977). Capital, Volume III. London: Lawrence and Wishart.

Mighell, R., \& Jones, M. (1963). Vertical co-ordination and contract farming (USDA Report no. 19). Washington, DC: U.S. Department of Agriculture.

Minot, N. (2011). Contract farming in sub-Saharan Africa: Opportunities and challenges. Paper prepared for the policy seminar "Smallholder-led Agricultural Commercialization and Poverty Reduction: How to Achieve It?” Kigali, Rwanda, April 18-22, 2011. Retrieved March 5, 2017 from https://www.researchgate.net/profile/Nicholas_Minot/publication/ 
267953148_Contract_Farming_in_sub-Saharan_Africa_Opportunities_and_Challenges/ links/ 54b92449ocf2c27adc491715.pdf

Moore, J. (2011). Transcending the metabolic rift: A theory of crises in the capitalist world ecology. The Journal of Peasant Studies, 38(1), 1-46.

Neocosmos, M. (1986). Marx's third class: Capitalist landed property and capitalist development. The Journal of Peasant Studies, 13(3), 5-44.

Oya, C. (2012). Contract farming in sub-Saharan Africa: A survey of approaches, debates and issues. Journal of Agrarian Change, 12(1), 1-33.

Van der Ploeg, J. D. (2013). Peasants and the art of farming: A Chayanovian manifesto. Halifax, NS: Fernwood.

Porter, G., \& Phillips-Howard, K. (1997). Comparing contracts: An evaluation of contract schemes in Africa. World Development, 25(2), 227-238.

Post, C. (1995). The agrarian origins of US capitalism: The transformation of the northern countryside before the Civil War. The Journal of Peasant Studies, 22(3), 380-445.

Prowse, M. (2012). Contract farming in developing countries: a review. Paris: Agence Française de Développement.

Sartorius, K., \& Kirsten, J. (2005). The boundaries of the firm: Why do sugar producers outsource sugarcane production? Management Accounting Research, 16(1), 81-99.

Sayer, A. (1992). Method in social science. London: Routledge.

Sayer, A. (2000). Realism and social science. London: SAGE Publications.

Sayer, A., \& Walker, R. (1992). The new social economy: Reworking the division of labour. Oxford: Blackwell.

Scott, A. J. (1984). Industrial organization and the logic of intra-metropolitan location. Economic Geography, 6o, 1-26.

Sender, J., \& Johnston, D. (2004). Searching for a weapon of mass production in rural Africa: Unconvincing arguments for landreform. Journal of Agrarian Change, 4(1 \& 2), 142164 .

Smalley, R., Sulle, E., \& Malale, L. (2014). The role of the state and foreign capital in agricultural commercialisation: The case of sugarcane outgrowers in Kilombero District, Tanzania (Working Paper 106). Future Agricultures Consortium. Retrieved November 5, 2014 from

http://www.plaas.org.za/sites/default/files/publications-pdf/FAC_Working_Paper_1 o6.pdf

Starosta, G. (2010). Global commodity chains and the Marxian law of value. Antipode, 2(2), 433-465.

Ton, G., Vellema, W., D’Haese, M., Desiere, S., Weituschat, S., Brouwer, J. H. D., \& van Hoeven, J. T. (2015). Systematic review of the effectiveness of contract farming for income and food security of smallholder in low-and middle income countries (3ie Systematic Review-SR6.1088 Protocol). International Initiative for Impact Evaluation-3ie. $\begin{array}{llll}\text { Retrieved } & \text { March } & 3, & 2017\end{array}$ http://library.wur.nl/WebQuery/wurpubs/fulltext/377875

Wallerstein, I., \& Hopkins, T. (1994). Commodity chains: Construct and research. In G. Gereffi, \& M. Korzeniewicz (Eds.), Commodity chains and global capitalism. Westport, CT: Praeger. 
Watts, M. (1994). Life under contract: Contract farming, agrarian restructuring and flexible accumulation. In P. Little, \& M. Watts (Eds.), Living under contract: Contract farming and agrarian transformation in sub-Saharan Africa (pp. 21-77). Madison, WI: University of Wisconsin Press.

Watts, M. (2010). The Southern question: Agrarian questions of labour and capital. In A. Akram-Lodhi, \& C. Kay (Eds.), Peasants and globalization: Political economy, rural transformation and the agrarian question (pp. 262-287). New York: Routledge.

Weis, T. (2010). The accelerating biophysical contradictions of industrial capitalist agriculture. Journal of Agrarian Change, 10(3), 315-341.

Williams, S., \& Karen, R. (1985). Agribusiness and the small farmer. Boulder, CO: Westview Press.

Wilson, J. (1986). The political economy of contract farming. Review of Radical Political Economy, 18(4), 47-70. 